Article

\title{
Optimal Replenishment for Perishable Products with Inventory-Dependent Demand and Backlogging under Continuous and Discrete Progressive Payments
}

\author{
Longfei $\mathrm{He}^{1, *}$, Han Gao ${ }^{1}$, Xiao Zhang ${ }^{1, *}$, Qinpeng Wang ${ }^{2, *}$ and Chenglin $\mathrm{Hu}^{3, *}$ \\ 1 College of Management and Economics, Tianjin University, Tianjin 300072, China; hlf819@163.com \\ 2 School of Management Science and Engineering, Hebei University of Economics and Business, \\ Shijiazhuang 050061, China \\ 3 College of Intelligent Manufacturing, Tianjin Sino-German University of Applied Sciences, \\ Tianjin 300350, China \\ * Correspondence: helf@tju.edu.cn (L.H.); hlf@tju.edu.cn (X.Z.); qinpeng@heuet.edu.cn (Q.W.); \\ chenglinhu8@gmail.com (C.H.)
}

Received: 26 August 2018; Accepted: 26 September 2018; Published: 16 October 2018

\begin{abstract}
Managing material and cash flows attracts concerns of physical and financial departments in most companies. We, therefore, focus on optimizing the replenishment policy for a channel with stock-dependent demand considering item deterioration and order backlogging under two financial schemes of progressive trade credit periods. We take both the continuous payment regime (CPR) and discrete payment regime (DPR) into account in the progressive trading process, which generates ten distinct scenarios. We show that the profit functions may not necessarily be concave and accordingly give a corresponding computing algorithm, which relaxes the convexity assumptions of objective functions in the existing literature and consequently enrich the research. We address the formulation characterization and the logic of pursuing global optimization from models arising in all settings. Computational studies and simulations are conducted to illustrate the effect of various parameters on the optimal replenishing policy and profit. Numerical experiments show that the CPR scheme is dominantly prior to DPR for long replenishment time intervals, whereas it is exactly the opposite for short time intervals. We also examine the impact of the shortage cost and deteriorating rate on optimum ordering policy and channel performance. Finally, future research directions are addressed in the end.
\end{abstract}

Keywords: replenishing policy; stock-dependent demand; order backlogging; deterioration; progressive payments; operations optimization

\section{Introduction}

Managing material and cash flows is the common concern for both physical and financial departments both in most of business organizations [1]. In this sense, it is usually viewed as the interesting interface of financing and operations to seek trade-off between inventory control and accounting (including purchasing payment). For the transaction in supply chains, it is common in practice for the supplier to offer the downstream buyer different paying schemes after the transfer of the goods occurs, namely the Progressive Payment Scheme that has been extensively studied. This kind of strategy of payment delay is offered as an incentives of inspiring buyers to enlarge their purchasing amount, which is expected to incur similar effects resulting from a variety of incentive contracts [2] for enhancing supply chain performance. Aggarwal and Jaggi [3], Sarker et al. [4] and Soni and Shah [5] discuss the optimal ordering policy under the progressive payment scheme. In recent years, considering the progressive payment scheme, Pal [6] and Sen and Saha [7] also investigate the optimal 
decisions of supply chain. From here we see that the progressive payment scheme is one of the most significant factors in ordering decisions, which is also the key factor for the research in this paper.

For the characteristics of market demand, practitioners in practice and academia have both observed the phenomenon that the demand rate is usually affected by the inventory on hand, which has been addressed by dozens of studies since Levin et al. [8]. Shukla et al. [9] developed two different mathematical models in terms of the different types of holding cost function with stock-level dependent demand for obtaining the optimal order quantity. Stock-dependent products is described as a key factor influencing the optimization problem in Fu and Chen [10], in which two functions of minimizing total cost with or without shortage are developed. Thus, it is important for a firm confronting the stock-dependent demand to find the optimum ordering policy associating its stock-on-hand evolving path in order to maximize (or minimize) the total profit (cost) in the long run.

On the other hand, some products may deteriorate depending on the storage conditions. The deteriorating items are classified into two categories in Li et al. [11], the first category are the decayed items, such as meat, fruits, vegetables, the other category are items that lose value, such as computer chips and mobile phone. The deteriorating products in this paper focus on the first category. As we all know, the deterioration of items shows a large impact on inventory decisions of firms. Therefore, how to control the items deterioration to mitigate its influence on inventory is a considerable question, which has gained much attention in academia such as Wang [12], Dye [13], Majumder et al. [14] and Ardak et al. [15].

We investigate the optimal reordering problem of deteriorating items with inventory-dependent demand in the scenario with a plausible delay payment scheme newly proposed. For this purpose, we clearly define two different delay payment regimes, Continuous Payment Regime (hereinafter referred as CPR) and Discrete Payment Regime (hereinafter referred as DPR) as follows: (1) Continuous Payment Regime: over some specific period, the buyer pays the supplier the money owed using the instantaneous revenue continuously until all purchasing cost has been paid back completely; (2) Discrete Payment Regime: the buyer accumulates revenue by depositing it in bank and pay money at some discrete specific time instants until all purchasing cost are cleared off.

The reminder of this paper is organized as follows. In Section 2, the relevant literatures are reviewed. In Section 3, we formulate the problem as well as define notations. In Section 4, we develop models in a variety of scenarios considering CPR and DPR in terms of the variation of permissible delay time, respectively. In Section 5, we firstly give a unified computational algorithm and then conduct computational experiments and sensitivity analyses to obtain some managerial insights. Future research and conclusions are offered in Section 6.

\section{Literature Review}

This study is typically featured in three aspects, namely, deterioration, stock-dependent demand and financially progressive payment credits. We therefore give a brief review over the literature from these three tracks. An increasing body of literature has focused on inventory control problems with deterioration in different settings. Wang [12], Dye [13] and Chang and [16] discussed the replenishment policy for deteriorating item considering backlogging. Yang et al. [17] formulate the inventory system for non-instantaneous deteriorating items with the price-dependent demand, aiming to find the optimal selling price and replenishment cycle time to maximize the total profit. Khanra et al. [18] assume the deterioration rate is constant, and developed the economic ordering quantity (EOQ) model for deteriorating item. Further, Singh and Pattnayak [19] explore the EOQ model by extending the aforesaid paper, suppose the deterioration rate is variable rather than constant. More studies related to the effect of deteriorating rate on inventory, and one can refer to Majumder et al. [14], Ardak et al. [15] and Pal and Samanta [20].

There is also a number of studies on modeling progressive payment schemes. Aggarwal and Jaggi [3], Sarker et al. [4] and Soni and Shah [5] are among early researches to develop some optimal ordering/quantity policies for system under progressive payment scheme. Chung [21] developed a 
new solution procedure to overcome the shortcoming of that in Goyal et al. [22] in terms of the classical EOQ model considering payment delay. Mohan et al. [23] explored the optimal replenishment policy for multi-item in three different situations: the permissible delay is negative, is less than the replenishment interval and is greater than the replenishment interval. Recently, Chen and Teng [24] proposed a simple arithmetic-geometric method to solve the extended EOQ model under a conditionally permissible delay in payments. The same year, Li et al. [25] describe the inventory games where the retailer's delay in payments is permitted by the supplier, and proved that the core of inventory games is nonempty under a permissible delay. For more research on the replenishment considering the permissible delay in payment also see Li et al. [1], Vandana and Sharma [26], Sen and Saha [7] and Pal [6].

For the track of stock-dependent demand, Min and Zhou [27] addressed a deterministic inventory model with demand backlogging permitted and exploited a solution procedure for optimum replenishment policy in a similar way as Lee and Dye [28]. In a more complicated situation, Min et al. [29] considered sequential delayed payments between the retailer with her supplier and customers, respectively and focused on optimizing retailer's average profit. Although Sana [30] and Sana [31] also both considered stock dependent demand, they moved to study multiple products considering sales efforts' effect on demand as well. However, these two studies do not take delay payment into consideration while only showing the optimal replenishment policies. Extending the single-firm problem to the supply chain situation, Zhou et al. [32] analyzed the interactions of ordering and paying issues in a non-cooperative game theory framework. Their work opens the door to study stock-dependent demand featured ordering and trading policies with intertwined decision-makings in supply chain scenario. There are also a series of EOQ-based models with stock-dependent demand, such as Ray and Chaudhuri [33], Teng and Chang [34], Teng and Ouyang [35], Tyagi et al. [36], Shukla et al. [9], Ghosh et al. [37] and Fu and Chen [10].

Among the most relevant research to and our study, Teng et al. [38] provide a comprehensive extensions by allowing a non-zero ending inventory, bounded inventory capacity, and deterioration based on Soni and Shah [5]. Glock et al. [39] correct some formulation errors in Soni and Shah [5] and research a new scenario in which the retailer's credit interest rate is greater than the supplier's charging interest rate. However, they focus on variant problems using a similar framework of modeling and a solving method with that in Soni and Shah [5]. Different from the above studies, we not only simultaneously consider three factors of deterioration, stock-dependent demand and financially progressive payment credits, but also incorporate two delayed payment schemes and permit order backlogging, which is closer to reality yet seldom examined together.

Compared with the aforementioned existing literatures only adopting a DPR-like policy, our study considers CPR and DPR simultaneously in two main aspects: (1) under CPR, we initially formulate the reordering policy optimization problem, develop models and exploit associated solving processes; (2) under DPR, we reconstruct the formulation and modeling and moreover we permit the time point for clearing off purchasing cost (including charging interest) either in CPR or in DPR, which does not necessarily just hit the time instant $T$ exactly as in Soni and Shah [5] and Teng et al. [38]. Namely, for $Z(T)$ the inventory level at time $T$ equals to zero does not mean that the retailer needs to settle all unpaid money just at $T$. Relaxating the constraint of the clearing off time point at $T$ is significant and will substantially affect the problem formulation, modeling and solving process. Second, when modeling and solving our problem, we remove the pre-conditions and assumptions that all objective functions are convex ensured by putting constraints upon the decision variable $T$ which has been shown frequently in Soni and Shah [5], Teng et al. [38], Glock et al. [39] and so on. This relaxation is managerially significant again due to its impact on modeling and solving process and of course the optimal solution since the objective function should not be confined or necessarily convex (or concave) from the point of practice. 


\section{Preliminaries and Notations}

Consider a retailer purchases finished goods from the upstream supplier in repeated cycles. The market demand facing the retailer is dependent on the timely stock level on hand, which is commonly assumed extensively in the literature and found in reality. Suppose the items are perishable goods that can deteriorate over time. Therefore, the inventory is depleted at three factors of stock level, deteriorating and constant consumption rates. Moreover, assume the retailer permits the order backlogging in each cycle and the unfilled orders will be served in the succeeding period. Hence, the schematic curve of inventory level over time can be plotted as shown in Figure 1, where the retailer receives $Q+V$ units goods from the supplier at the beginning of each replenishment period $(t=0)$ and immediately put $V$ units of products to meet the backlogging orders inherited from the preceding period, and accordingly $Q$ units are held as the initial inventory of the present period. In each replenishment cycle, the retailer can earn interest income from depositing sales revenue in the bank until the deadline of the permitted credit periods. The time instant $T_{\mathcal{C}}$ starts the shortage interval implying that the retailer needs to decide suitable $V$ for backlogging all orders generated in this meantime.

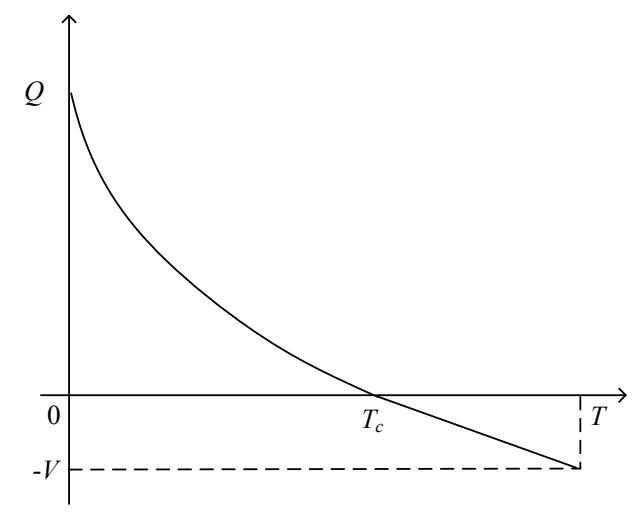

Figure 1. The change of the inventory level over time.

In addition to the ordering and replenishment problem mentioned above, we also incorporate the issue of payment in instalment for goods into the study, which interwines inventory ordering policy to substantially impact the system profit since the payment by instalment can also bring penalty and/or income. Therefore, considering the perishable goods with deterioration, we intend to investigate the system optimal ordering policy with shortage and stock-dependent demand under two trading regimes and credits. Specifically, several cases are discussed according to the variation of credit periods.

For the necessity of problem formulating, the following assumptions are adopted throughout the whole paper: (i) The demand rate, $R(t)=a+b Z(t)+\theta Z(t)$, is a function of the inventory level $Z(t)$, where $a, b$ and $\theta$ are intrinsic demand, sensitivity parameter and deteriorating rate to inventory level, respectively, with $a>b>0,0 \leq \theta<1$ and $R(t)=a$ when $T_{c} \leq t \leq T$. (ii) Lead-time is neglected and replenishment usually occurs at the beginning of each period. Furthermore, assume the supplier's capacity is infinite without defective item. (iii) as for the payment schedule, the retailer will charge additional fees for the unpaid balances as follows: nothing in the case of payment clearance before time $M$, at a rate of $I_{\mathcal{C}_{1}}$ supposing payment clearance during time interval $[M, N]$ and a rate of $I_{\mathcal{C}_{2}}$ given payment clearance after $N$ with $I_{\mathcal{C}_{2}}>I_{\mathcal{C}_{1}}>I_{e}$ and $I_{e}$ denoting interest the rate of banks.

\section{Mathematical Models}

According to the illustrations and assumptions in Section 2, the depletion of inventory is due to three aspects: the constant demand $a$, the stock-depended demand and the deterioration in the 
products. Thereby, we use the differential equations below to govern the instantaneous state of inventory at time $t$

$$
\begin{gathered}
d Z(t) / d t=-a-b Z(t)-\theta Z(t), \quad 0 \leq t \leq T_{\mathcal{C}} \\
d Z(t) / d t=-a, \quad T_{\mathcal{c}}<t \leq T
\end{gathered}
$$

Then the stock level can be obtained below in view of the boundary conditions $Z\left(T_{\mathcal{c}}\right)=0$ and $Z(0)=Q$.

$$
\begin{gathered}
Z(t)=\frac{a}{b+\theta}\left[e^{(b+\theta)\left(T_{c}-t\right)}-1\right], \quad 0 \leq t \leq T_{\mathcal{c}} \\
Z(t)=-a\left(t-T_{c}\right), \quad T_{\mathcal{c}}<t \leq T
\end{gathered}
$$

Combining the condition $\mathrm{Z}(T)=-V$ and Function (4) yields

$$
T_{c}=T-V / a
$$

Thus, the inventory level in period $[0, T]$ can be summarized as below

$$
Z(t)= \begin{cases}\frac{a}{b+\theta}\left[e^{(b+\theta)(T-V / a-t)}-1\right], & 0 \leq t \leq T-V / a \\ a(T-V / a-t), & T-V / a<t \leq T\end{cases}
$$

Additionally, the retailer's other costs per unit time after value assignment include ordering cost $A / T$, shortage cost $c_{0} V / T$, and holding cost $Z(t)=\left\{\begin{array}{ll}\frac{a}{b+\theta}\left[e^{(b+\theta)(T-V / a-t)}-1\right], & 0 \leq t \leq T-V / a \\ a(T-V / a-t), & T-V / a<t \leq T\end{array}\right.$.

In view of diverse credit periods with different penalty interests charged by supplier as mentioned previously, four major cases with subcases will be discussed as follows, after which we will compare all cases under different progressive payment schemes to recognize the optimum replenishing policy.

\subsection{Case $1 T_{c}<T \leq M<N$}

We first consider an extreme but simplest situation where the replenishment cycle is less than the first credit time $M$ (shown in Figure 2). In this case, assume the retailer intends to exploit the advantage of no penalty incurred in the case of payment clearance before the first credit time $M$. Thus, the rational retailer will definitely clear all outstanding payment at $M$ since she can deposit the sales revenue in the bank to earn interest at the rate of $I_{e}$. Considering the costs incurred by ordering, wholesaling, shortage and inventory holding, the retailer's problem is to determine suitable replenishing cycle time and shortage to maximize her annual profit, which can be expressed as:

$$
\begin{aligned}
\underset{(T, V)}{\operatorname{Max}} A P_{1}(T, V)=\frac{1}{T}\left\{p\left[\int_{0}^{T_{c}} R(t) d t+V\right]+p I_{e} V M+p I_{e} \int_{0}^{T_{c}} R(t)(M-t) d t\right. \\
\left.-c(Q+V)-A-c_{0} V-h \int_{0}^{T_{c}} Z(t) d t\right\} \\
\text { s.t. }\left\{\begin{array}{l}
T_{c}=T-V / a \\
T_{c}<T \leq M<N \\
V \leq V_{0}
\end{array}\right.
\end{aligned}
$$

The first term, the sum of second and third terms and the rest in the curly braces of above Equation (7) represent sales revenue, interest earned and manifold aforesaid costs, respectively.

4.2. Case $2 M<T_{c}<N\left(M<T_{c} \leq N<T\right.$ or $\left.M<T_{c}<T \leq N\right)$

We now consider the situation in which the replenishment time interval can be divided into two parts: $[0, M]$ and $[M, T]$ (shown in Figure 3). The profit of retailer includes both sales revenue and interest earned during the credit period $[0, M]$. While penalty interest is charged at rate of $I_{\mathcal{L}_{1}}$ during in 
the period $[M, T]$, the wise retailer will repay the wholesale cost at the time $M$ to avoid the penalty interest charged by the supplier. The interest earned during the credit period $[0, M]$ takes the form:

$$
I E_{[0, M]}=p I_{e} V M+p I_{e} \int_{0}^{M} R(t)(M-t) d t
$$

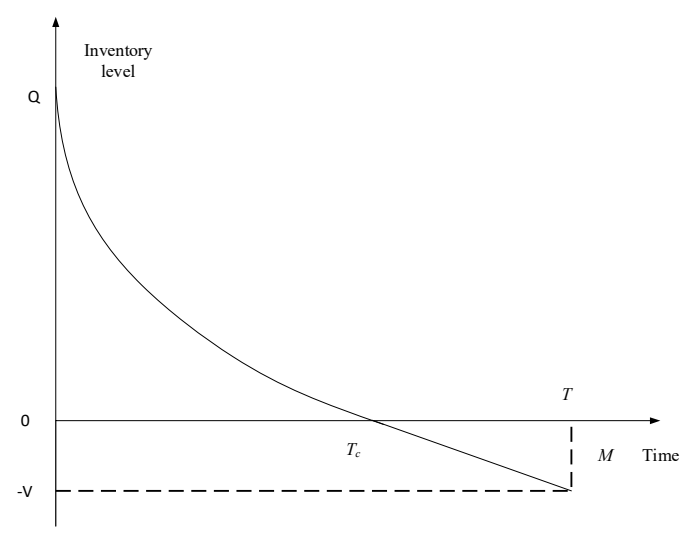

Figure 2. Inventory level over time in case 1.

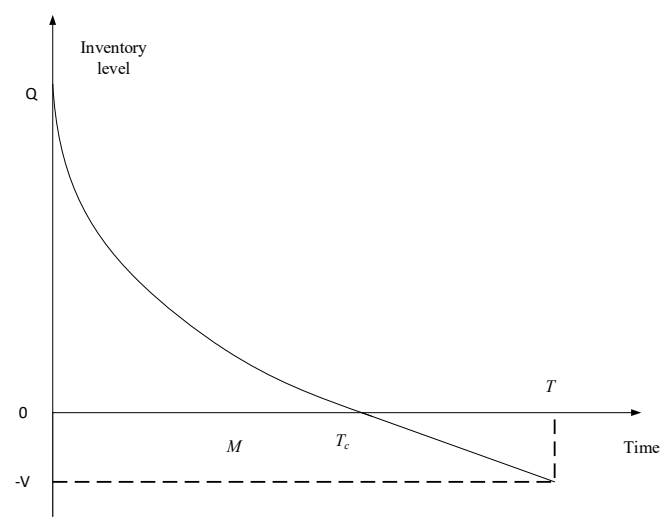

Figure 3. Inventory level over time in case 2.

The remaining deposit of the retailer after repaying the wholesale cost to the supplier at time $M$ can be expressed as follows:

$$
U_{2-1}=p V+p \int_{0}^{M} R(t) d t+p I_{e} V M+p I_{e} \int_{0}^{M} R(t)(M-t) d t-c(Q+V)
$$

The first two terms of the Equation (9) represents the sales revenue, the sum of the third and fourth terms denotes the earned interest of the retailer by depositing the sales revenue in the bank, and the last term of the function represents the wholesale cost.

It should be noted that whether the revenue including sales revenue and earned interest is sufficient to repay all the wholesale cost. Considering the problem, two subcases are discussed below. 


\subsubsection{Subcase 2-1 The Revenue Being Sufficient to Repay the Wholesale Cost at Time $M$}

The retailer repays all the wholesale cost at time $M$, according to the Equation (9), immediately, the annual profit of retailer in the whole replenishment time interval takes the form:

$$
\begin{aligned}
& \underset{(T, V)}{\operatorname{Max}} A P_{2-1}(T, V)=\frac{1}{T}\left\{p \int_{M}^{T_{c}} R(t) d t+p I_{e} \int_{M}^{T_{c}} R(t)(T-t) d t+U_{2-1}\left[1+I_{e}(T-M)\right]-A-c_{0} V-h \int_{0}^{T_{c}} Z(t) d t\right\} \\
& \text { s.t. }\left\{\begin{array}{l}
U_{2-1}=p V+p \int_{0}^{M} R(t) d t+p I_{e} V M+p I_{e} \int_{0}^{M} R(t)(M-t) d t-c(Q+V) \\
M<T_{c}<N \\
p\left[\int_{0}^{M} R(t) d t+V\right]+p I_{e} V M+p I_{e} \int_{0}^{M} R(t)(M-t) d t \geq c(Q+V) \\
V \leq V_{0}
\end{array}\right.
\end{aligned}
$$

\subsubsection{Subcase 2-2 The Revenue Is Insufficient to Repay the Wholesale Cost at Time $M$}

In this subcase, we consider that the revenue is insufficient to repay the wholesale cost in the permissible credit period. For the wise retailer, all revenue including sales revenue and earned interest will be spent on repaying the wholesale cost at time $M$ to avoid paying higher penalty interest. The unpaid money accordingly at time $M$ is shown as:

$$
U(M)=c(Q+V)-p V-p \int_{0}^{M} R(t) d t-p I_{e} V M-p I_{e} \int_{0}^{M} R(t)(M-t) d t
$$

Obviously, the unpaid money must be paid by retailer and the penalty interest will be incurred beyond the credit period $M$. Meanwhile, the supplier provides two ways for the retailer regarding how to pay the remaining balance: continuous and discrete payment regimes.

\section{Subcase 2-2a Continuous Payment Regime (CPR)}

With the continuous payment regime, the retailer continuously uses the instantaneous revenue to repay the debt until all wholesale costs are completely paid off. Denote $t_{a}$ the time at which the unpaid balance is cleared off under the continuous payment regime through the paper, $M<t_{a} \leq T_{c}$. Especially, the profit of the retailer in the period $\left(T_{c}<t_{a}\right)$ is negative, to facilitate the research, the situation is excluded in this model.

The unpaid money during the $\left[M, T_{c}\right]$ can be calculated from

$$
d U(t) / d t=-p R(t)+I_{\mathcal{C}_{1}} U(t), M<t<T_{\mathcal{C}}
$$

Combining the Equations (12) and (13), the unpaid money takes the form:

$$
U(t)=\frac{p a \theta e^{-I_{c_{1}} t}}{I_{\mathcal{C}_{1}}(b+\theta)}+\frac{a b p e^{-I_{c_{1}} t} e^{(b+\theta)(T-V / a-t)}}{(b+\theta)\left(b+\theta+I_{\mathcal{C}_{1}}\right)}+U(M)-\frac{p a \theta e^{-I_{c_{1}} M}}{I_{\mathcal{C}_{1}}(b+\theta)}+\frac{a b p e^{-I_{c_{1}} t} e^{(b+\theta)(T-V / a-M)}}{(b+\theta)\left(b+\theta+I_{\mathcal{C}_{1}}\right)}
$$

The clearance point $t_{a}$ can be obtained by letting $U(t)=0$. Furthermore, the earned interest in the interval $\left[t_{a}, T_{c}\right]$ is

$$
I E_{2-2 a}=p \int_{t_{a}}^{T_{c}} R(t) d t+p I_{e} \int_{t_{a}}^{T_{c}} R(t)(T-t) d t
$$

Immediately, the annual profit of the retailer during the whole cycle period can be expressed as:

$$
\begin{aligned}
& \underset{(T, V)}{\operatorname{Max}} A P_{2-2 a}(T, V)=\frac{1}{T}\left[p \int_{t_{a}}^{T_{c}} R(t) d t+p I_{e} \int_{t_{a}}^{T_{c}} R(t)(T-t) d t-A-c_{0} V-h \int_{0}^{T_{c}} Z(t) d t\right] \\
& \text { s.t. }\left\{\begin{array}{l}
U(M)>0, U\left(T_{c}\right)<0 \\
t_{a}=\arg \left\{U\left(t_{a}\right)=0\right\} \\
M<T_{c}<N, M<t_{a} \leq T_{c} \\
V \leq V_{0}
\end{array}\right.
\end{aligned}
$$


Subcase 2-2b Discrete Payment Regime (DPR)

Different from the continuous payment regime, the retailer will pay all the remaining debt at the specific time $t_{b}$ with the discrete payment regime. Similarly, the case with $T<t_{b}$ is not discussed in the paper.

The charged interest during the period $\left[M, t_{b}\right]$ can be written as:

$$
I C_{2-2 b}=I_{C_{1}} U(M)\left(t_{b}-M\right)
$$

The earned interest during the period $\left[M, t_{b}\right]$ can be written as:

$$
I E_{2-2 b}=p I_{e} \int_{M}^{t_{b}} R(t)\left(t_{b}-t\right) d t
$$

The revenue during the period $\left[t_{b}, T_{c}\right]$ can be written as:

$$
R_{2-2 b}=p \int_{t_{b}}^{T_{c}} R(t) d t+p I_{e} \int_{t_{b}}^{T_{c}} R(t)(T-t) d t
$$

Considering the retailer settles all unpaid balance at time $t_{b}$, the following equation holds

$$
p \int_{M}^{t_{b}} R(t) d t+p I_{e} \int_{M}^{t_{b}} R(t)\left(t_{b}-t\right) d t=U(M)+I_{c_{1}} U(M)\left(t_{b}-M\right)
$$

The left-hand side (LHS) of above equation represents the sales revenue and interest earned in the interval $\left[M, t_{b}\right]$, and the right-hand side (RHS) denotes the unpaid balance and interest charged. Solving the equation below can obtain $t_{b}$

$$
\phi(x)=p \int_{M}^{x} R(t) d t+p I_{e} \int_{M}^{x} R(t)(x-t) d t-U(M)-I_{c_{1}} U(M)(x-M), M<x \leq T_{c}
$$

where $\phi(M)<0, \phi\left(t_{b}\right)=0, \phi\left(T_{c}\right)>0$. Subsequently, the annual profit of the retailer during the whole cycle period is shown as:

$$
\begin{array}{r}
\underset{(T, V)}{\operatorname{Max}} A P_{2-2 b}(T, V)=\frac{1}{T}\left[p \int_{t_{b}}^{T_{c}} R(t) d t+p I_{e} \int_{t_{b}}^{T_{c}} R(t)(T-t) d t-A-c_{0} V-h \int_{0}^{T_{c}} Z(t) d t\right] \\
\text { s.t. }\left\{\begin{array}{l}
\phi(M)<0, \phi\left(T_{c}\right) \geq 0 \\
t_{b}=\arg \left\{\phi\left(t_{b}\right)=0\right\} \\
M<T_{\mathcal{c}}<N, M<t_{b} \leq T_{\mathcal{c}} \\
V \leq V_{0}
\end{array}\right.
\end{array}
$$

\subsection{Case $3 M<N<T_{c}<T$}

Consider the different penalty interest rates over progressive delays in payments with the relation $M<N<T_{c}<T$ (shown in Figure 4). In this case, for necessity of analysis the whole cycle period is divided to three intervals $[0, M],[M, N]$ and $[N, T]$, each of which corresponds to a subcase as discussed below. Similarly, whether the retailer can settle all unpaid balance at time $M$ generates the following two subcases.

\subsubsection{Subcase 3-1 The Revenue Is Sufficient to Repay the Wholesale Cost at Time $M$}

This case is no different from the Case 2-1 except for the credit period, which will not be reiterated here. 


\subsubsection{Subcase 3-2 The Revenue Is Insufficient to Repay the Wholesale Cost at Time $M$}

Consider the subcase in which total purchasing cost cannot be settled at time $M$. As mentioned previously, assume the supplier offers the retailer two progressive payment regimes, i.e. continuous and discrete payment regimes, whose essential difference reflects the way the retailer behaves continuously or discretely for doing the payment. Then we explore the subcases below.

\section{Subcase 3-2a Continuous Payment Regime (CPR)}

With the continuous payment regime, the retailer continuously transfers the instantaneous income to defray the debt until all balance is cleared off at a certain time $t_{a}$. However, there are different penalty interests incurred when the clearance point $t_{a}$ belongs to the intervals $[M, N]$ or $\left[N, T_{\mathcal{C}}\right]$ due to the principles described in supplier's installment payment schemes. Hence, the Subcase 3-2a can be further decomposed into two separate parts below.

Subcase 3-2a' $M<t_{a} \leq N$

This subcase is similar to the Subcase 2-2a as described previously, so it will not be addressed here to avoid the repetition.

Subcase 3-2a" $N<t_{a} \leq T_{c}$

In this subcase, the retailer is not able to settle all unpaid balance in the two progressive periods. Under continuous payment regime, the retailer will pay the penalty interest at the rate $I_{\mathcal{C}_{1}}$ during the time interval $[M, N]$ and $I_{\mathcal{C}_{2}}$ during the period $\left[N, T_{C}\right]$. Then the differential equations below hold

$$
d U(t) / d t=\left\{\begin{array}{l}
-p R(t)+I_{c_{1}} U(t), \quad M<t \leq N \\
-p R(t)+I_{\mathcal{C}_{2}} U(t), N<t \leq T_{\mathcal{C}}
\end{array}\right.
$$

According to the Equation (12) and conditions $U(N)>0$ and $U\left(T_{\mathcal{C}}\right) \leq 0$, the unpaid balance is governed by the equations below

$$
U(t)=\left\{\begin{array}{l}
\frac{p a \theta\left(e^{-I_{C_{1}} t}-e^{-I_{c_{1}} M}\right)}{I_{c_{1}}(b+\theta)}+\frac{a b p e^{-I_{C_{1}} t}\left[e^{(b+\theta)(T-V / a-t)}-e^{(b+\theta)(T-V / a-M)}\right]}{(b+\theta)\left(b+\theta+I_{C_{1}}\right)}+U(M), M<t \leq N \\
\frac{p a \theta\left(e^{\left.-I_{\mathcal{C}_{2}}{ }^{t}-e^{-I_{C_{2}} N}\right)}\right.}{I_{\mathcal{C}_{2}}(b+\theta)}+\frac{a b p e^{-I_{C_{2}} t}\left[e^{(b+\theta)(T-V / a-t)}-e^{(b+\theta)(T-V / a-N)}\right]}{(b+\theta)\left(b+\theta+I_{\mathcal{C}_{2}}\right)}+U(N), N<t \leq T_{\mathcal{C}}
\end{array}\right.
$$

Hence, retailer's annual profit in whole period in Subcase 3-2a" can be expressed as:

$$
\begin{aligned}
& \underset{(T, V)}{\operatorname{Max} A P_{3-a^{\prime \prime}}(T, V)=\frac{1}{T}\left[p \int_{t_{a}}^{T_{c}} R(t) d t+p I_{e} \int_{t_{a}}^{T_{c}} R(t)(T-t) d t-A-c_{0} V-h \int_{0}^{T_{c}} Z(t) d t\right]} \\
& \text { s.t. }\left\{\begin{array}{l}
U(M)>0, U(N)>0, U\left(T_{c}\right) \leq 0 \\
t_{a}=\arg \left\{U\left(t_{a}\right)=0\right\} \\
M<N<t_{a}<T_{c} \\
V \leq V_{0}, T \leq T_{0}
\end{array}\right.
\end{aligned}
$$

Subcase 3-2b Discrete Payment Regime (DPR)

Now we pause here to discuss the subcase under the other progressive payment regime, i.e. discrete payment regime. As the name suggests, DPR is just on the opposite of CPR, namely, the retailer deposits money in some discrete times until all unpaid balance is cleared off. at time $t_{b}$. Similarly, depending on intervals $[M, N]$ or $\left[N, T_{c}\right]$, to which the point $t_{b}$ belongs, we further discuss the problem in two separate situations, respectively.

Subcase $3-2 b^{\prime} M<t_{b} \leq N$

Similarly, this subcase is the same as the Subcase $2-2 b$, so we again omit the deriving process. 
Subcase $3-2 b^{\prime \prime} N<t_{b} \leq T_{c}$

Considering the penalty interest charged by the supplier, the retailer tries to settle the unpaid balance by time $N$ and then he pays off all the debt at the time $t_{b}$ under the discrete payment regime. Hence, the unpaid balance at time $N$ can be written as:

$$
U(N)=I_{\mathcal{C}_{1}} U(M)(N-M)+U(M)-p \int_{M}^{N} R(t) d t-p I_{e} \int_{M}^{N} R(t)(N-t) d t
$$

Accordingly, the interest charged and the interest earned during the credit period $\left[N, t_{b}\right]$ are shown respectively as:

$$
\begin{gathered}
I C_{3-2 b^{\prime \prime}}=I_{\mathcal{C}_{2}} U(N)\left(t_{b}-N\right) \\
I E_{3-2 b^{\prime \prime}}=p I_{e} \int_{N}^{t_{b}} R(t)\left(t_{b}-t\right) d t
\end{gathered}
$$

Note that the retailer can square up all unpaid balance at the time $t_{b}$ only when her accumulated income equals the sum of unpaid money and charged interest, that is the equation below holds

$$
p \int_{N}^{t_{b}} R(t) d t+p I_{e} \int_{N}^{t_{b}} R(t)\left(t_{b}-t\right) d t=U(N)+I_{c_{2}} U(N)\left(t_{b}-N\right)
$$

where $t_{b}$ is determined by the following function as well as its boundary conditions

$$
\phi(x)=p \int_{N}^{x} R(t) d t+p I_{e} \int_{N}^{x} R(t)(x-t) d t-U(N)-I_{\mathcal{C}_{2}} U(N)\left(t_{b}-N\right), N<x \leq T_{c}
$$

with $\phi(N)<0, \phi\left(t_{b}\right)=0, \phi\left(T_{c}\right)>0$.

Given the above, the retailer's average annual profit can be expressed as follows

$$
\begin{aligned}
& \underset{(T, V)}{\operatorname{Max}} A P_{3-2 b^{\prime \prime}}(T, V)= \frac{1}{T}\left[p \int_{t_{b}}^{T_{c}} R(t) d t+p I_{\mathcal{e}} \int_{t_{b}}^{T} R(t)(T-t) d t-A-h \int_{0}^{T_{c}} Z(t) d t\right] \\
& \text { s.t. }\left\{\begin{array}{l}
\phi(M)>0, \phi(N)>0, \phi\left(T_{c}\right) \leq 0 \\
t_{b}=\arg \left\{\phi\left(t_{b}\right)=0\right\} \\
M<N<t_{b} \leq T_{c} \\
V \leq V_{0}, T \leq T_{0}
\end{array}\right.
\end{aligned}
$$

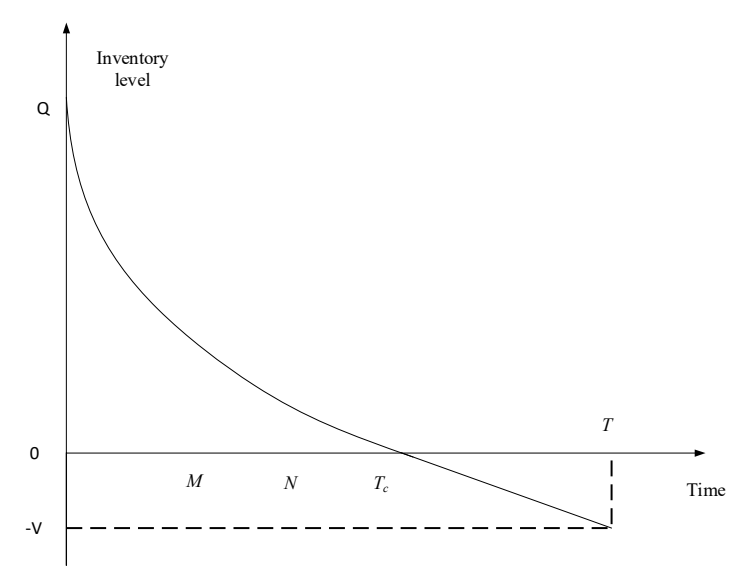

Figure 4. Inventory level over time in case 3.

4.4. Case $4 T_{c}<M<T\left(T_{c}<M<N<T\right.$ or $\left.T_{c}<M<T<N\right)$

Now we shed the light on the case in which the relationship $T_{\mathcal{c}}<M<T$ holds, which can be decomposed into sub-cases $T_{\mathcal{C}}<M<N<T$ or $T_{\mathcal{c}}<M<T<N$ (shown in Figure 5). In view of the 
retailer's rationality, she will return a large amount money at time $M$ while she earns income from sales and deposit interest. Then retailer's remaining bank savings after payment at time $M$ can be expressed as follows:

$$
U(M)=p\left[\int_{0}^{T_{c}} R(t) d t+V\right]+p I_{e} V M+p I_{e} \int_{0}^{T_{c}} R(t)(M-t) d t-c(Q+V)
$$

where the first term in RHS of Equation (32) represents the sales revenue, the last term the total purchasing cost and the second term the earned interest of the retailer by depositing the sales revenue in the bank. Furthermore, the remaining savings of retailer is continuously deposited in bank to earn the interest during the credit period $[M, T]$, and it takes the form

$$
I E_{4}=I_{e} U(M)(T-M)
$$

Hence, the average annual profit of retailer takes can be formulated as follows

$$
\begin{aligned}
& \underset{(T, V)}{\operatorname{Max}} A P_{4}(T, V)=\frac{1}{T}\left\{U(M)\left[1+I_{e}(T-M)\right]-A-c_{0} V-h \int_{0}^{T_{c}} Z(t) d t\right\} \\
& \text { s.t. }\left\{\begin{array}{l}
U(M)=p\left[\int_{0}^{T_{c}} R(t) d t+V\right]+p I_{e} V M+p I_{e} \int_{0}^{T_{c}} R(t)(M-t) d t-c(Q+V) \geq 0 \\
T_{c}<M<N \\
V \leq V_{0}, T \leq T_{0}
\end{array}\right.
\end{aligned}
$$

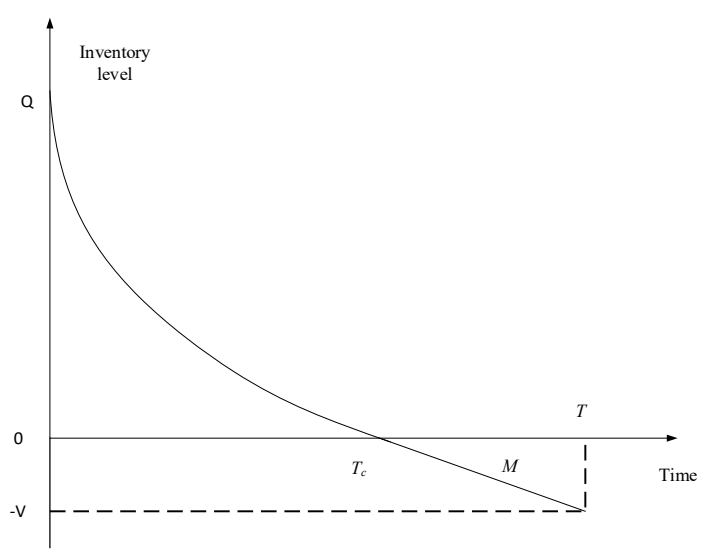

Figure 5. Inventory level over time in case 4.

\subsection{The Characterization and Logic of Global Optimization}

Given all the formulation above, there exist, in total, ten subcases explored in terms of two progressive payment approaches and a comparison of trade credits and the replenishing cycle, which is shown below:

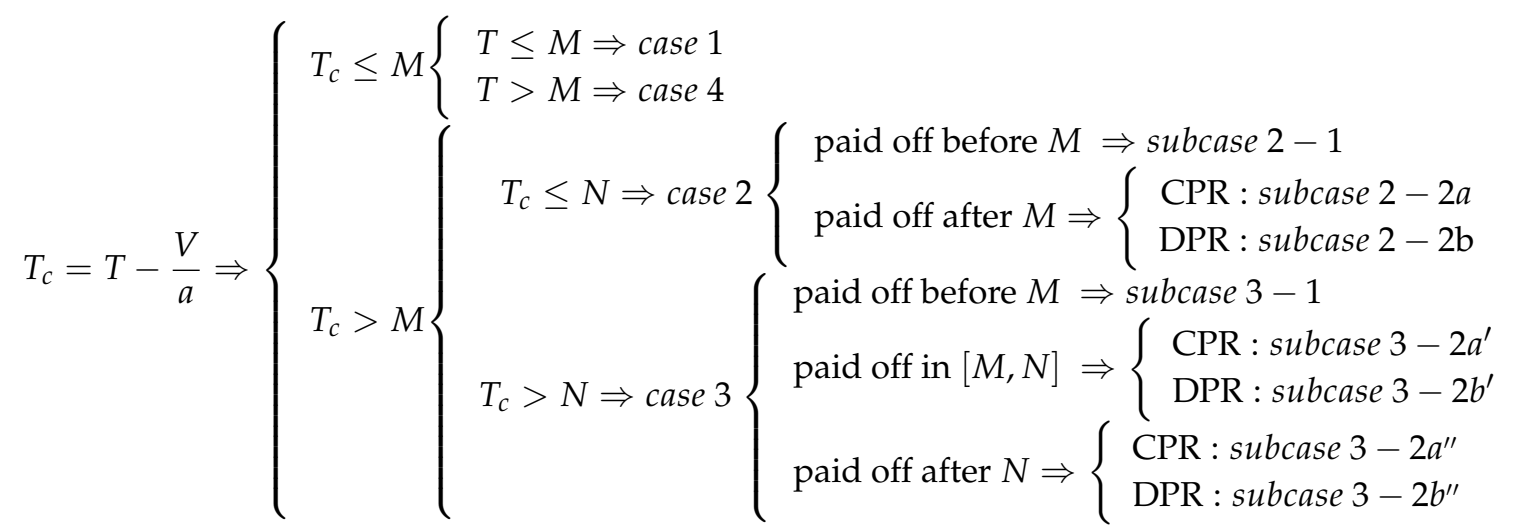


Essentially, it is a process to pursue global optimization based on multiple piecewise nonlinear optimizations. Its logic is to first solve each subcase by getting the local optimum solution, and then compare all of these ten local optimum values to determine the global optimum solution. In view of the complication and nonlinearity of the whole problem, we are not able to give the elegantly analytical solution, so an effective way is to conduct numerical experiments to investigate the problem's characterization as well as managerial insights. Note that the detailed exposition of formulation and representations for all ten cases are addressed in the Appendix.

\section{Numerical Examples}

To illustrate the previously developed models, the paper utilizes Particle Swarm Optimization (PSO), an extensively used intelligent optimization algorithm, to solve the problem. For more detailed information about the PSO, one can refer to Shi and Eberhart [40] and Eberhart and Shi [41]. Here some computational experiments are proposed under given parameters below, $A=200, c=20, c_{0}=3$, $p=30, h=6, a=1000, b=0.25, M=17 / 365, N=35 / 365, \theta=0.1, I_{e}=12 \%, I_{c_{1}}=13 \%$ and $I_{c_{2}}=20 \%$. In addition, assume the upper bounds of shortage quantity and replenishment time interval are $V_{0}=500$ and $T_{0}=2$, respectively. The scale of particle swarm is 100 , the iteration times 300 and the calculation time is 10 .

Example 1. The annual profit (maximum between CPR and DPR) of the retailer is increasing in the replenishment time interval originally, however, with the growth of the replenishment time interval, the annual profit presents a downtrend. This is the same as our intuition that the annual profit is decreasing in shortage quantity. In addition, the annual profit is zero in some situations as shown in Figure 6. The reason for rendering the phenomenon is that the constraint condition $T_{c}=T-V / a \geq 0$ is not satisfied. In view of the situation, we define the annual profit equals to zero when $T_{c}=T-V / a<0$. Observing Figure 7, when there is a short replenishment time interval, the profit of the retailer in the discrete payment regime (DPR) is greater than that in the continuous payment regime (CPR), while CPR is superior to DPR with the long replenishment time interval. The result reveals that it is beneficial for the retailer to choose DPR with a short replenishment time interval, otherwise, the CPR will be the best choice.

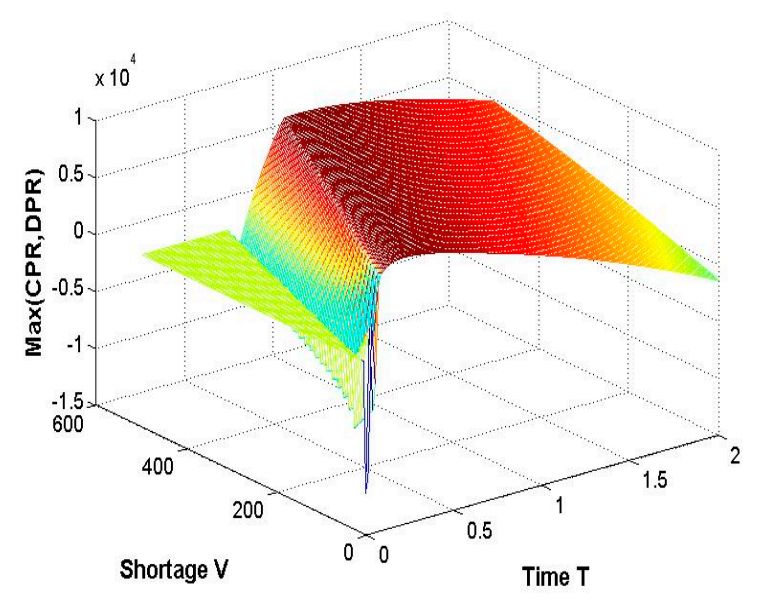

Figure 6. The annual profit of retailer. 


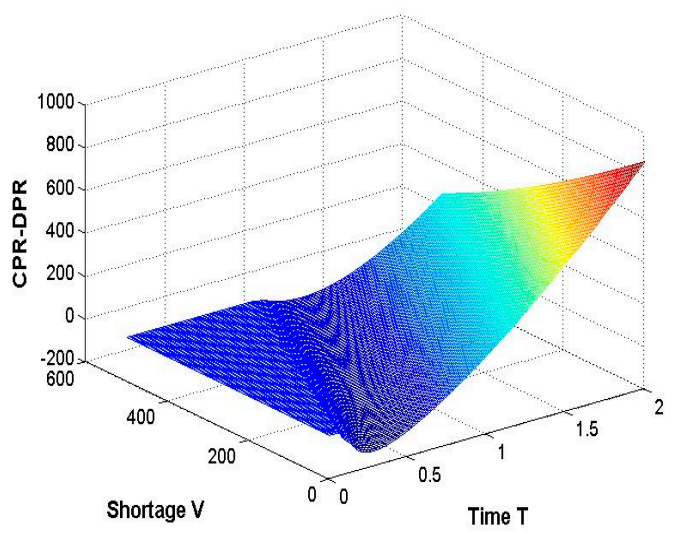

Figure 7. The difference of the annual profit between CPR and DPR.

Example 2. Figures 8 and 9 depict how the unit shortage cost and deteriorating rate influence on the retailer's profit in the two different payment regimes, and some results can be obtained from the figures. First, the profit is decreasing in unit shortage cost (the same result described aforesaid) and deteriorating rate. Second, the time hitting the profit peak shifts right with the increase of shortage quantity, that is, the retailer obtains the maximum profit in a short replenishment time interval with a small shortage quantity. Third, originally, the profit of retailer in DPR is higher than that in CPR, while, as the growth of replenishment time interval, the CPR is superior to the DPR. The result illustrates when there is a short replenishment time interval, and it is beneficial to the retailer with DPR, otherwise, the CPR will be chosen by the retailer (the same result as obtained in Example 1).
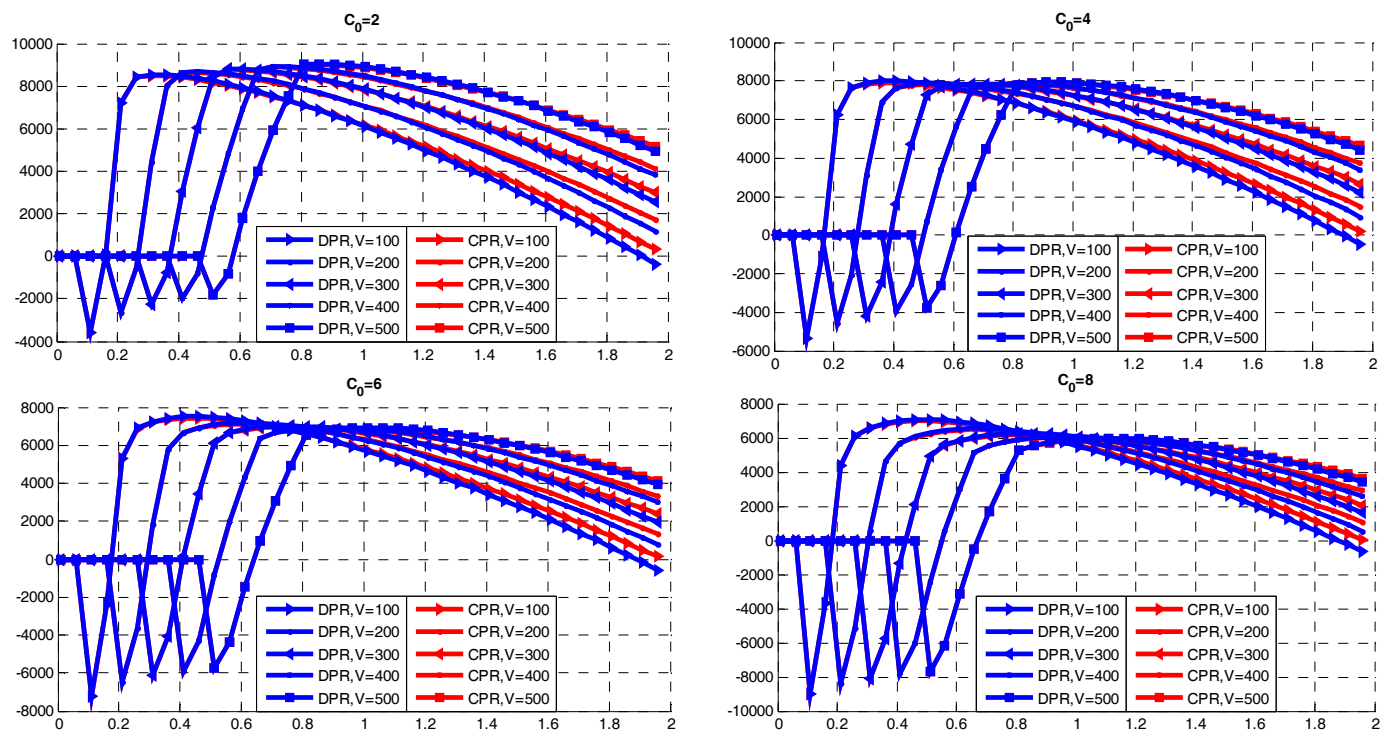

Figure 8. The annual profit versus $c_{0}$ variation. 

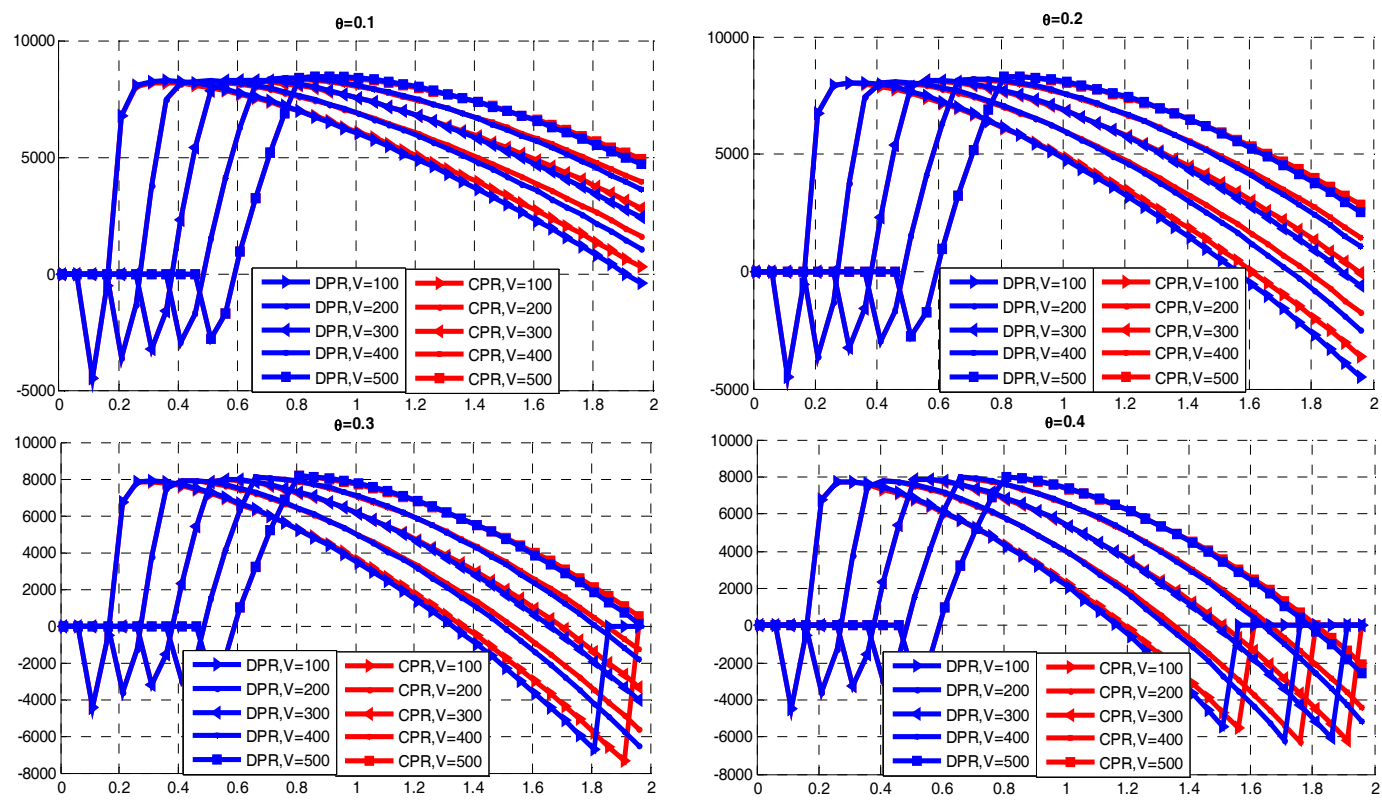

Figure 9. The annual profit versus $\theta$ variation.

Example 3. Replenishment time interval, order quantity and profit of the retailer are decreasing in unit shortage cost, as shown in Table 1, and some information is reflected in this phenomenon. With the increases of the unit shortage cost, the retailer decreases the replenishment time interval and order quantity by increasing the replenishment times for reducing the shortage cost. Nevertheless, the profit of the retailer is still decreasing in the shortage cost. In addition, the shortage quantity closes to the maximum shortage quantity with a low shortage cost. However, there is no shortage with the high shortage cost.

Table 1. Effect of $c_{0}$ on decision parameters.

\begin{tabular}{ccccc}
\hline$c_{0}$ & $\boldsymbol{T}$ & $\boldsymbol{V}$ & $\overline{\boldsymbol{Q}}$ & $\boldsymbol{A P}$ \\
\hline 2 & 0.8167 & 497.7667 & 835.1714 & 9057.6313 \\
3 & 0.8832 & 491.0036 & 911.3325 & 8467.8100 \\
4 & 0.2180 & 0 & 226.4905 & 8410.6412 \\
5 & 0.2178 & 0 & 226.3488 & 8410.6407 \\
6 & 0.2176 & 0 & 226.1124 & 8410.6383 \\
\hline
\end{tabular}

Example 4. Observing Tables 2 and 3, some conclusions can be found. As the increase of stock-dependent demand parameter $b$ and the credit periods $M$ and $N$, the annual profit of retailer is increasing, while it is decreasing in penalty interest rates $I_{\mathcal{C}_{1}}$ and $I_{\mathcal{C}_{2}}$. The phenomenon indicates that when the demand is more dependent on the stock-level or there is a long credit period, the retailer should increase the ordering quantity and extend the replenishment time interval for getting high profits. However, considering the penalty interest, the retailer must shorten the replenishment time interval and reduce the ordering quantity to mitigate the negative effect of penalty interest. In reality, firms should focus on two issues for getting high profit. First, investigate the sensitivity of the consumer on inventory to evaluate the value of $b$, then decide to increase or reduce the order quantity and replenishment cycle interval for profiting more in term of the value of $b$. Second, retailers should strengthen the bargaining power with upstream companies to get the long credit periods and low penalty interest rate. 
Table 2. Effect of $b, M$ and $I_{c_{1}}$ on decision parameters.

\begin{tabular}{|c|c|c|c|c|c|}
\hline \multirow[b]{2}{*}{$b$} & \multicolumn{5}{|c|}{$M$} \\
\hline & $\begin{array}{c}20 / 365 \\
\left(I_{c_{1}}=15 \%\right)\end{array}$ & $\begin{array}{c}30 / 365 \\
\left(I_{c_{1}}=15 \%\right)\end{array}$ & $\begin{array}{c}40 / 365 \\
\left(I_{c_{1}}=15 \%\right)\end{array}$ & $\begin{array}{c}40 / 365 \\
\left(I_{c_{1}}=25 \%\right)\end{array}$ & $\begin{array}{c}40 / 365 \\
\left(I_{c_{1}}=35 \%\right)\end{array}$ \\
\hline \multicolumn{6}{|l|}{0.15} \\
\hline$T$ & 0.8441 & 0.8605 & 0.8927 & 0.8837 & 0.8716 \\
\hline$V$ & 488.4832 & 489.1813 & 471.2593 & 486.4183 & 472.1411 \\
\hline $\bar{Q}$ & 860.3828 & 878.2310 & 891.2670 & 914.0644 & 892.2445 \\
\hline$\widetilde{A P}$ & 8404.4491 & 8477.7351 & 8537.7501 & 8532.4892 & 8526.0081 \\
\hline \multicolumn{6}{|l|}{0.2} \\
\hline$T$ & 0.8646 & 0.8697 & 0.8988 & 0.8976 & 0.8846 \\
\hline$V$ & 493.0853 & 491.1428 & 490.7041 & 489.9936 & 481.6495 \\
\hline $\bar{Q}$ & 886.0368 & 892.0257 & 924.8738 & 923.5452 & 909.9451 \\
\hline$\widetilde{A P}$ & 8448.1874 & 8521.0173 & 8589.4862 & 8588.9267 & 8581.8973 \\
\hline \multicolumn{6}{|l|}{0.25} \\
\hline$T$ & 0.8866 & 0.8950 & 0.9082 & 0.9083 & 0.8938 \\
\hline V & 500 & 500 & 498.2631 & 498.0957 & 488.6078 \\
\hline $\bar{Q}$ & 913.9737 & 923.5793 & 939.1119 & 939.1504 & 923.8838 \\
\hline$A P$ & 8497.2087 & 8573.3328 & 8645.2952 & 8645.1166 & 8636.5492 \\
\hline \multicolumn{6}{|l|}{0.3} \\
\hline$T$ & 0.8981 & 0.9134 & 0.9198 & 0.9193 & 0.9011 \\
\hline$V$ & 496.6770 & 500 & 500 & 499.8087 & 489.0922 \\
\hline $\bar{Q}$ & 932.1163 & 949.5101 & 957.0938 & 956.4898 & 936.9380 \\
\hline$\widetilde{A P}$ & 8540.1315 & 8621.0579 & 8696.7935 & 8696.4078 & 8686.3345 \\
\hline \multicolumn{6}{|l|}{0.35} \\
\hline$T$ & 0.9102 & 0.9313 & 0.9386 & 0.9346 & 0.9091 \\
\hline V & 490.3020 & 497.0977 & 498.5971 & 498.0310 & 489.3622 \\
\hline $\bar{Q}$ & 952.4840 & 976.6036 & 985.1538 & 980.3983 & 951.3962 \\
\hline$\widetilde{A P}$ & 8584.4509 & 8670.4279 & 8749.4627 & 8747.2465 & 8738.3301 \\
\hline
\end{tabular}

Table 3. Effect of $b, N$ and $I_{\mathcal{C}_{1}}$ on decision parameters.

\begin{tabular}{|c|c|c|c|c|c|}
\hline \multirow[b]{2}{*}{$b$} & \multicolumn{5}{|c|}{$N$} \\
\hline & $\begin{array}{c}50 / 365 \\
\left(I_{c_{2}}=30 \%\right)\end{array}$ & $\begin{array}{c}70 / 365 \\
\left(I_{c_{2}}=30 \%\right)\end{array}$ & $\begin{array}{c}90 / 365 \\
\left(I_{c_{2}}=30 \%\right)\end{array}$ & $\begin{array}{c}90 / 365 \\
\left(I_{c_{2}}=40 \%\right)\end{array}$ & $\begin{array}{c}90 / 365 \\
\left(I_{c_{2}}=50 \%\right)\end{array}$ \\
\hline \multicolumn{6}{|l|}{0.15} \\
\hline$T$ & 0.8595 & 0.8701 & 0.8701 & 0.8701 & 0.8633 \\
\hline V & 491.9821 & 500 & 500 & 500 & 494.4807 \\
\hline $\bar{Q}$ & 876.8582 & 887.7219 & 887.7933 & 887.7933 & 880.7802 \\
\hline$\widetilde{A P}$ & 8480.8280 & 8488.3131 & 8488.3071 & 8488.3071 & 8483.1111 \\
\hline \multicolumn{6}{|l|}{0.2} \\
\hline$T$ & 0.8729 & 0.8795 & 0.8749 & 0.8700 & 0.8617 \\
\hline$V$ & 495.9561 & 500 & 500 & 491.2119 & 488.7023 \\
\hline $\bar{Q}$ & 895.0049 & 901.9195 & 896.7598 & 892.3055 & 883.3820 \\
\hline$\widetilde{A P}$ & 8525.3818 & 8529.1272 & 8529.2760 & 8520.6942 & 8518.6131 \\
\hline \multicolumn{6}{|l|}{0.25} \\
\hline$T$ & 0.8836 & 0.8852 & 0.8868 & 0.8867 & 0.8868 \\
\hline$V$ & 498.4398 & 500 & 500 & 500 & 500 \\
\hline $\bar{Q}$ & 910.7060 & 912.3960 & 914.2018 & 914.1471 & 914.0690 \\
\hline$A P$ & 8570.8756 & 8572.3571 & 8572.3734 & 8572.3734 & 8572.3734 \\
\hline \multicolumn{6}{|l|}{0.3} \\
\hline$T$ & 0.8971 & 0.8985 & 0.8995 & 0.9054 & 0.8962 \\
\hline$V$ & 498.5952 & 499.7340 & 500 & 500 & 495.6017 \\
\hline $\bar{Q}$ & 930.6382 & 932.0134 & 933.1913 & 940.1691 & 930.0751 \\
\hline$\widetilde{A P}$ & 8616.7980 & 8617.8926 & 8618.1521 & 8617.9222 & 8613.8861 \\
\hline \multicolumn{6}{|l|}{0.35} \\
\hline$T$ & 0.9001 & 0.9100 & 0.9134 & 0.9120 & 0.9101 \\
\hline$V$ & 494.9595 & 495.6477 & 500 & 498.8823 & 497.4994 \\
\hline $\bar{Q}$ & 939.3413 & 951.1595 & 954.3575 & 950.6287 & 953.2017 \\
\hline$\widetilde{A P}$ & 8661.7442 & 8662.6566 & 8666.9194 & 8665.8131 & 8664.4647 \\
\hline
\end{tabular}




\section{Concluding Remarks}

In this research, we investigated the optimizing ordering policy for a perishable product supply chain with stock-dependent demand facing items deterioration and order backlogging under progressive payment schemes. We considered the continuous payment regime (CPR) and discrete payment regime (DPR) both in the progressive trading process to generate piecewise nonlinear optimization problem of ten distinct scenarios. We demonstrated the characterization of problem formulation as well as the logic of exploring global optimization from all piecewise local optimizations. We further conducted computational studies and numerical simulation to illustrate the impact of parameters on the optimal ordering policy and channel performance.

Some key findings of this study are summarized as follows: (i) we decompose the problem into an equivalent set of multiple piecewise nonlinear optimizations and elaborate its formulation characterization and logic, which provides an integral approach for exploring the optimal replenishing policy in this specific problem. (ii) comparing the profits incurred by two progressive payment schemes implies that the relatively long replenishment cycle will let the retailer better off under CPR, whereas the relatively short cycle works better under DPR. Therefore, for firms, it is best choice to repay the money by CPR when there is long replenishment cycle, otherwise, the DPR will be the best way for getting more profits. (iii) reducing order backlogging quantity may benefit retailer's pursuing greater profit in short time range. Thus, the one who wants to maximize the profit in a short time would better reduce order backlogging quantity. (iv) the increasing of stock-dependent demand parameter and the length of the progressive credit period will push up the ordering quantity and replenishment cycle for getting more profit. The result implies two directions that the firms should pay much attention: first, increasing the sensitivity of the consumer on inventory, and second, enhancing bargaining power to obtain a long progressive credit period.

Our research contributes to the track of managing material and cash flows. The proposed model can be extended in several ways. For example, the model may extend the constant deterioration rate to time-varying deterioration. Furthermore, retailers are also likely to provide the permissible delay in payment to consumers in day-to-day deal; then the model will become more complex, and more significant results may be explored.

Author Contributions: L.H. contributed to design, conduct this research and write and revise the whole paper. H.G. and X.Z. contributed to jointly conduct the research and solve some of models and are responsible for doing the numerical studies. Q.W. and C.H. contributed to join the research, discuss models, give valuable suggestions and revise the paper.

Funding: This work is partially supported by NSFC Grants (No. 91646118, 71701144, 71602142, 71528002). It is also supported by Natural Science Foundation of Hebei Province of China under Grant No. G2017207015 and Humanity and Social Science Youth Foundation of Ministry of Education of China under Grant No. 18YJC630183.

Conflicts of Interest: The authors declare no conflict of interest. 


\section{Notation/Description}

The notations used in this paper are summarized as below:

$h$

$p$

$c$

A

$M$

$N$

$Q$

$c_{0}$

$V$

$V_{0}$

$T$

$T_{0}$

$T_{C}$

$\bar{Q}$

$t_{a}$

$t_{b}$

$A P(T, V)$
Inventory holding cost per unit per year excluding interest charges

Unit selling price

Unit wholesale cost $(c<p)$

Fixed ordering cost/ order

The first permissible delay in settling account (i.e., the trade credit period)

The second permissible delay in settling account and $N>M$

The on-hand inventory at the beginning of each replenishment period

Unit shortage cost

The shortage quantity (the decision variable)

The maximum permissible shortage quantity

The replenishment cycle time

The maximum replenishment time interval

The time point that on-hand products are depleted to zero

The order quantity at the beginning of the replenishment period the time at which the unpaid balance is cleared off under continuous payment regime the time at which the unpaid balance is cleared off under discrete payment regime The annual profit of the retailer

\section{Appendix A} (subcases).

This appendix addresses the detailed exposition of formulation and representations for all ten cases

Case 1

$$
\begin{aligned}
& \underset{(T, V)}{\operatorname{Max}} A P_{1}(T, V)=\frac{1}{T}\left\{p\left[\int_{0}^{T_{c}} R(t) d t+V\right]+p I_{e} V M+p I_{e} \int_{0}^{T_{c}} R(t)(M-t) d t-c(Q+V)-A-c_{0} V-h \int_{0}^{T_{c}} Z(t) d t\right\} \\
& =\frac{1}{T}\left\{\left(p+p I_{\mathcal{e}} M\right)\left[V+\frac{a \theta T_{c}}{b+\theta}+\frac{a b\left(e^{(b+\theta) T_{c}}-1\right)}{(b+\theta)^{2}}\right]-p I_{\mathcal{e}}\left[\frac{a \theta\left(T_{c}\right)^{2}}{2(b+\theta)}-\frac{a b T_{c}}{(b+\theta)^{2}}+\frac{a b\left(e^{(b+\theta) T_{c}}-1\right)}{(b+\theta)^{3}}\right]\right. \\
& \left.-c(Q+V)-A-c_{0} V-h\left[\frac{a\left(e^{(b+\theta) T_{c}}-1\right)}{(b+\theta)^{2}}-\frac{a T_{c}}{b+\theta}\right]\right\} \\
& \text { s.t. }\left\{\begin{array}{l}
T_{c}=T-V / a, T_{c}<T \leq M<N \\
V \leq V_{0}
\end{array}\right.
\end{aligned}
$$

Case 2

Subcase 2-1

$$
\begin{gathered}
\underset{(T, V)}{\operatorname{Max}} T P_{2-1}(T, V)=\frac{1}{T}\left\{p \int_{M}^{T_{c}} R(t) d t+p I_{e} \int_{M}^{T_{c}} R(t)(T-t) d t+U_{2-1}\left[1+I_{e}(T-M)\right]-A-c_{0} V-h \int_{0}^{T_{c}} Z(t) d t\right\} \\
=\frac{1}{T}\left\{\left(p+p I_{e} T\right)\left[\frac{a \theta}{b+\theta}\left(T_{\mathcal{c}}-M\right)+\frac{a b\left(e^{(b+\theta)\left(T_{c}-M\right)}-1\right)}{(b+\theta)^{2}}\right]+U_{2-1}\left[1+I_{e}(T-M)\right]-A-c_{0} V-h\left[\frac{a\left(e^{(b+\theta) T_{c}}-1\right)}{(b+\theta)^{2}}-\frac{a T_{c}}{b+\theta}\right]\right. \\
\left.-p I_{\mathcal{e}}\left[\frac{a \theta\left[\left(T_{c}\right)^{2}-M^{2}\right]}{2(b+\theta)}-\frac{a b\left[M e^{(b+\theta)\left(T_{c}-M\right)}-T_{c}\right]}{(b+\theta)^{2}}+\frac{a b\left[e^{(b+\theta)\left(T_{c}-M\right)}-1\right]}{(b+\theta)^{3}}\right]\right\} \\
\qquad . t .\left\{\begin{array}{l}
T_{c}=T-V / a \\
U_{2-1}=\left\{p V+p I_{e} V M+\left(p+p I_{e} M\right)\left[\frac{a \theta}{b+\theta} M+\frac{a b\left(e^{(b+\theta) T_{c}}-e^{(b+\theta)\left(T_{c}-M\right)}\right)}{(b+\theta)^{2}}\right]\right. \\
\left.-p I_{e}\left[\frac{a \theta M^{2}}{2(b+\theta)}-\frac{a b M e^{(b+\theta)\left(T_{c}-M\right)}}{(b+\theta)^{2}}+\frac{a b\left(e^{(b+\theta) T_{c}}-e^{(b+\theta)\left(T_{c}-M\right)}\right)}{(b+\theta)^{3}}\right]-c(Q+V)\right\} \geq 0 \\
M<T_{c}<N, V \leq V_{0}
\end{array}\right.
\end{gathered}
$$


Subcase 2-2

Subcase 2-2a

$$
\begin{aligned}
& \underset{(T, V)}{\operatorname{Max}} A P_{2-2 a}(T, V)=\frac{1}{T}\left[p \int_{t_{a}}^{T_{c}} R(t) d t+p I_{e} \int_{t_{a}}^{T_{c}} R(t)(T-t) d t-A-c_{0} V-h \int_{0}^{T_{c}} Z(t) d t\right] \\
& =\frac{1}{T}\left\{\left(p+p I_{e} T\right)\left[\frac{a \theta}{b+\theta}\left(T_{c}-t_{a}\right)+\frac{a b\left(e^{(b+\theta)\left(T_{c}-t_{a}\right)}-1\right)}{(b+\theta)^{2}}\right]-p I_{e}\left[\frac{a \theta\left[\left(T_{c}\right)^{2}-t_{a}{ }^{2}\right]}{2(b+\theta)}-\frac{a b\left[t_{a} e^{(b+\theta)\left(T_{c}-t_{a}\right)}-T_{c}\right]}{(b+\theta)^{2}}+\frac{a b\left[e^{(b+\theta)\left(T_{c}-t_{a}\right)}-1\right]}{(b+\theta)^{3}}\right]\right. \\
& \left.-A-c_{0} V-h\left[\frac{a}{(b+\theta)^{2}}\left(e^{(b+\theta)(T-V / a)}-1\right)-\frac{a(T-V / a)}{b+\theta}\right]\right\}
\end{aligned}
$$

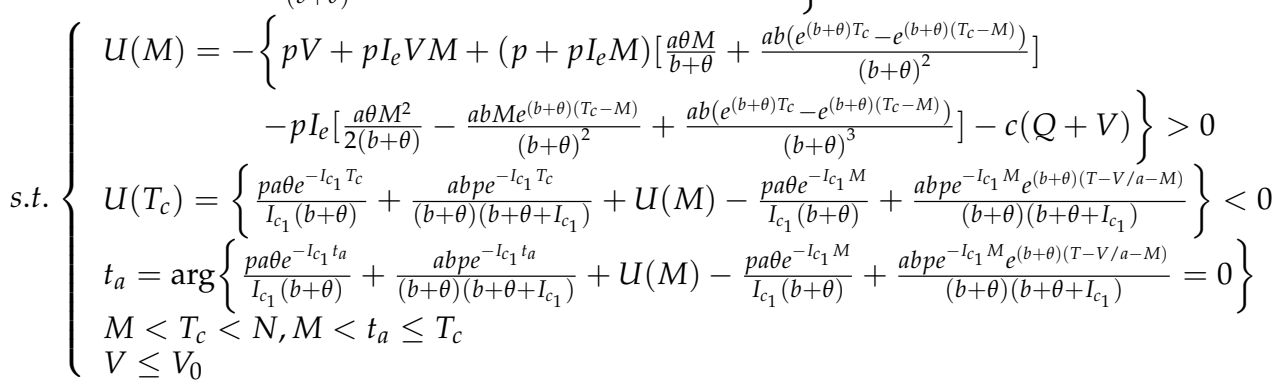

Subcase 2-2b

$$
\begin{gathered}
\underset{(T, V)}{\operatorname{Max}} A P_{2-2 b}(T, V)=\frac{1}{T}\left[p \int_{t_{b}}^{T_{c}} R(t) d t+p \gamma \int_{t_{b}}^{T_{c}} R(t)(T-t) d t-A-h \int_{0}^{T_{c}} Z(t) d t\right] \\
=\frac{1}{T}\left\{\left(p+p I_{e} T\right)\left[\frac{a \theta}{b+\theta}\left(T_{c}-t_{b}\right)+\frac{a b\left(e^{(b+\theta)\left(T_{c}-t_{b}\right)}-1\right)}{(b+\theta)^{2}}\right]-A-c_{0} V-h\left[\frac{a\left(e^{(b+\theta)(T-V / a)}-1\right)}{(b+\theta)^{2}}-\frac{a(T-V / a)}{b+\theta}\right]\right. \\
\left.-p I_{e}\left[\frac{a \theta\left[\left(T_{c}\right)^{2}-t_{b}{ }^{2}\right]}{2(b+\theta)}-\frac{a b\left[t_{b} e^{(b+\theta)\left(T_{c}-t_{b}\right)}-T_{c}\right]}{(b+\theta)^{2}}+\frac{a b\left[e^{(b+\theta)\left(T_{c}-t_{b}\right)}-1\right]}{(b+\theta)^{3}}\right]\right\}
\end{gathered}
$$$$
\text { s.t. }\left\{\begin{array}{rl}
T_{\mathcal{C}}=T- & V / a \\
\phi(M)= & \left\{p V+p I_{\mathcal{e}} V M+\left(p+p I_{\mathcal{e}} M\right)\left[\frac{a \theta}{b+\theta} M+\frac{a b\left(e^{(b+\theta) T_{\mathcal{c}}}-e^{(b+\theta)\left(T_{c}-M\right)}\right)}{(b+\theta)^{2}}\right]\right. \\
& \left.-p I_{\mathcal{e}}\left[\frac{a \theta M^{2}}{2(b+\theta)}-\frac{a b M e^{(b+\theta)\left(T_{c}-M\right)}}{(b+\theta)^{2}}+\frac{a b\left(e^{(b+\theta) T_{c}}-e^{(b+\theta)\left(T_{c}-M\right)}\right)}{(b+\theta)^{3}}\right]-c(Q+V)\right\}<0 \\
\phi\left(T_{\mathcal{C}}\right)= & \left\{p\left(1+I_{\mathcal{e}} T_{\mathcal{c}}\right)\left[\frac{a \theta}{b+\theta}\left(T_{\mathcal{C}}-M\right)+\frac{a b\left(e^{(b+\theta)\left(T_{c}-M\right)}-1\right)}{(b+\theta)^{2}}\right]+\phi(M)\left[1+I_{\mathcal{C}_{1}}\left(T_{\mathcal{C}}-M\right)\right]\right. \\
& \left.-p I_{\mathcal{e}}\left[\frac{a \theta\left(T_{c}{ }^{2}-M^{2}\right)}{2(b+\theta)}-\frac{a b\left(M e^{(b+\theta)\left(T_{c}-M\right)}-T_{c}\right)}{(b+\theta)^{2}}+\frac{a b\left(e^{(b+\theta)\left(T_{c}-M\right)}-1\right)}{(b+\theta)^{3}}\right]\right\} \geq 0 \\
t_{b}=\arg \{ & p\left(1+I_{\mathcal{e}} t_{b}\right)\left[\frac{a \theta}{b+\theta}\left(t_{b}-M\right)+\frac{a b\left(e^{(b+\theta)\left(T_{c}-M\right)}-e^{(b+\theta)\left(T_{c}-t_{b}\right)}\right)}{(b+\theta)^{2}}\right]+\phi(M)\left[1+I_{\mathcal{C}_{1}}\left(t_{b}-M\right)\right] \\
& \left.-p I_{\mathcal{e}}\left[\frac{a \theta\left(t_{b}{ }^{2}-M^{2}\right)}{2(b+\theta)}-\frac{a b\left(M e^{(b+\theta)\left(T_{c}-M\right)}-x e^{(b+\theta)\left(T_{c}-t_{b}\right)}\right)}{(b+\theta)^{2}}+\frac{a b\left(e^{(b+\theta)\left(T_{c}-M\right)}-e^{(b+\theta)\left(T_{c}-t_{b}\right)}\right)}{(b+\theta)^{3}}\right]=0\right\} \\
M<t_{b}<T_{\mathcal{C}}<N & N \\
V \leq V_{0}, T \leq T_{0}
\end{array}\right.
$$

$$
\begin{aligned}
\phi(x) & =p \int_{M}^{x} R(t) d t+p I_{e} \int_{M}^{x} R(t)(x-t) d t-U(M)-I_{\mathcal{C}_{1}} U(M)(x-M) \\
& =p\left(1+I_{\mathcal{e}} x\right)\left\{\frac{a \theta}{b+\theta}(x-M)+\frac{a b}{(b+\theta)^{2}}\left[e^{(b+\theta)(T-V / a-M)}-e^{(b+\theta)(T-V / a-x)}\right]\right\} \\
& -p I_{\mathcal{e}}\left\{\frac{a \theta\left(x^{2}-M^{2}\right)}{2(b+\theta)}-\frac{a b}{(b+\theta)^{2}}\left[M e^{(b+\theta)(T-V / a-M)}-x e^{(b+\theta)(T-V / a-x)}\right]+\frac{a b}{(b+\theta)^{3}}\left[e^{(b+\theta)(T-V / a-M)}-e^{(b+\theta)(T-V / a-x)}\right]\right\} \\
& -\left[1+I_{\mathcal{C}_{1}}(x-M)\right]\left\{\frac{a c}{(b+\theta)}\left[e^{(b+\theta)\left(T-\frac{V}{a}\right)}-1\right]+V c-p V\left(1+I_{e} M\right)-\frac{p a \theta M}{b+\theta}\left(1+I_{e} M / 2\right)\right. \\
& \left.-\frac{p a b}{(b+\theta)^{2}}\left[e^{(b+\theta)(T-V / a)}-e^{(b+\theta)(T-V / a-M)}+I_{\mathcal{e}} M e^{(b+\theta)(T-V / a)}\right]-\frac{p I_{e} a b}{(b+\theta)^{3}}\left[e^{(b+\theta)(T-V / a-M)}-e^{(b+\theta)(T-V / a)}\right]\right\} \\
& =p\left(1+I_{e} x\right)\left[\frac{a \theta}{b+\theta}(x-M)+\frac{a b\left(e^{(b+\theta)\left(T_{c}-M\right)}-e^{(b+\theta)\left(T_{c}-x\right)}\right)}{(b+\theta)^{2}}\right]+\phi(M)\left[1+I_{\mathcal{C}_{1}}(x-M)\right] \\
& -p I_{\mathcal{e}}\left[\frac{a \theta\left(x^{2}-M^{2}\right)}{2(b+\theta)}-\frac{a b\left(M e^{(b+\theta)\left(T_{c}-M\right)}-x e^{(b+\theta)\left(T_{c}-x\right)}\right)}{(b+\theta)^{2}}+\frac{a b\left(e^{(b+\theta)\left(T_{c}-M\right)}-e^{(b+\theta)\left(T_{c}-x\right)}\right)}{(b+\theta)^{3}}\right]
\end{aligned}
$$


Case 3

Subcase 3-1

$$
\begin{gathered}
\underset{(T, V)}{\operatorname{Max}} A P_{3-1}(T, V)=\frac{1}{T}\left\{p \int_{M}^{T_{c}} R(t) d t+p I_{e} \int_{M}^{T_{c}} R(t)(T-t) d t+U_{3-1}\left[1+I_{\mathcal{e}}(T-M)\right]-A-c_{0} V-h \int_{0}^{T_{c}} Z(t) d t\right\} \\
=\frac{1}{T}\left\{a\left(p+p I_{\mathcal{e}} T\right)\left[\frac{\theta\left(T_{c}-M\right)}{b+\theta}+\frac{b\left(e^{(b+\theta)\left(T_{c}-M\right)}-1\right)}{(b+\theta)^{2}}\right]+U_{3-1}\left[1+I_{e}(T-M)\right]-A-c_{0} V-a h\left[\frac{e^{(b+\theta) T_{c}}-1}{(b+\theta)^{2}}-\frac{T_{c}}{b+\theta}\right]\right. \\
\left.-a p I_{\mathcal{e}}\left[\frac{\theta\left[\left(T_{c}\right)^{2}-M^{2}\right]}{2(b+\theta)}-\frac{b\left[M e^{(b+\theta)\left(T_{c}-M\right)}-T_{c}\right]}{(b+\theta)^{2}}+\frac{b\left[e^{(b+\theta)\left(T_{c}-M\right)}-1\right]}{(b+\theta)^{3}}\right]\right\} \\
\text { s.t. }\left\{\begin{array}{l}
T_{c}=T-V / a, M<N<T_{\mathcal{c}} \\
U_{3-1}=\left\{p V+p I_{e} V M+a\left(p+p I_{e} M\right)\left[\frac{\theta}{b+\theta} M+\frac{b\left(e^{(b+\theta) T_{c}}-e^{(b+\theta)\left(T_{c}-M\right)}\right)}{(b+\theta)^{2}}\right]\right. \\
\left.-a p I_{e}\left[\frac{\theta M^{2}}{2(b+\theta)}-\frac{b M e^{(b+\theta)\left(T_{c}-M\right)}}{(b+\theta)^{2}}+\frac{b\left(e^{(b+\theta) T_{c}}-e^{(b+\theta)\left(T_{c}-M\right)}\right)}{(b+\theta)^{3}}\right]-c(Q+V)\right\} \geq 0
\end{array}\right.
\end{gathered}
$$

Subcase 3-2a'

$$
\begin{gathered}
\operatorname{Max}_{(T, V)} A P_{3-2 a^{\prime}}(T, V)=\frac{1}{T}\left[p \int_{t_{a}}^{T_{c}} R(t) d t+p I_{e} \int_{t_{a}}^{T_{c}} R(t)(T-t) d t-A-c_{0} V-h \int_{0}^{T_{c}} Z(t) d t\right] \\
=\frac{1}{T}\left\{\left(p+p I_{e} T\right)\left[\frac{a \theta}{b+\theta}\left(T_{c}-t_{a}\right)+\frac{a b\left(e^{(b+\theta)\left(T_{c}-t_{a}\right)}-1\right)}{(b+\theta)^{2}}\right]-A-c_{0} V-h\left[\frac{a\left(e^{(b+\theta)(T-V / a)}-1\right)}{(b+\theta)^{2}}-\frac{a(T-V / a)}{b+\theta}\right]\right. \\
\left.-p I_{e}\left[\frac{a \theta\left[\left(T_{c}\right)^{2}-t_{a}{ }^{2}\right]}{2(b+\theta)}-\frac{a b\left[t_{a} e^{(b+\theta)\left(T_{c}-t_{a}\right)}-T_{c}\right]}{(b+\theta)^{2}}+\frac{a b\left[e^{(b+\theta)\left(T_{c}-t_{a}\right)}-1\right]}{(b+\theta)^{3}}\right]\right\} \\
\text { s.t. }\left\{\begin{array}{l}
U(M)=-\left\{p V+p I_{e} V M+\left(p+p I_{e} M\right)\left[\frac{a \theta M}{b+\theta}+\frac{a b\left(e^{(b+\theta) T_{c}}-e^{(b+\theta)\left(T_{c}-M\right)}\right)}{(b+\theta)^{2}}\right]\right. \\
\left.-p I_{e}\left[\frac{a \theta M^{2}}{2(b+\theta)}-\frac{a b M e^{(b+\theta)\left(T_{c}-M\right)}}{(b+\theta)^{2}}+\frac{a b\left(e^{(b+\theta) T_{c}}-e^{(b+\theta)\left(T_{c}-M\right)}\right)}{(b+\theta)^{3}}\right]-c(Q+V)\right\}>0 \\
U(N)=\left\{\frac{p a \theta e^{-I_{c_{1} N} N}}{I_{c 1}(b+\theta)}+\frac{a b p e^{-I_{c_{1} N} N}}{(b+\theta)\left(b+\theta+I_{c 1}\right)}+U(M)-\frac{p a \theta e^{-I_{c_{1} M} M}}{I_{c 1}(b+\theta)}+\frac{a b p e^{-I_{c_{1}} M} e^{(b+\theta)(T-V / a-M)}}{(b+\theta)\left(b+\theta+I_{c 1}\right)}\right\}<0 \\
t_{a}=\arg \left\{\frac{p a \theta e^{-I_{c_{1}} t_{a}}}{I_{c 1}(b+\theta)}+\frac{a b p e^{-I_{c_{1}} t_{a}}}{(b+\theta)\left(b+\theta+I_{c 1}\right)}+U(M)-\frac{p a \theta e^{-I_{c_{1}} M}}{I_{c_{1}}(b+\theta)}+\frac{a b p e^{-I_{c_{1}} M} e^{(b+\theta)(T-V / a-M)}}{(b+\theta)\left(b+\theta+I_{c_{1}}\right)}=0\right\} \\
M<t_{a}<N<T_{c} \\
V \leq V_{0}, T \leq T_{0}
\end{array}\right.
\end{gathered}
$$

Subcase 3-2a"

$$
\begin{aligned}
& \underset{(T, V)}{\operatorname{Max}} A P_{3-2 \mathrm{a}^{\prime \prime}}(T, V)=\frac{1}{T}\left[p \int_{t_{a}}^{T_{c}} R(t) d t+p I_{\mathcal{e}} \int_{t_{a}}^{T_{c}} R(t)(T-t) d t-A-c_{0} V-h \int_{0}^{T_{c}} Z(t) d t\right] \\
& =\frac{1}{T}\left\{\left(p+p I_{e} T\right)\left[\frac{a \theta\left(T_{c}-t_{a}\right)}{b+\theta}+\frac{a b\left(e^{(b+\theta)\left(T_{c}-t_{a}\right)}-1\right)}{(b+\theta)^{2}}\right]-A-c_{0} V-h\left[\frac{a\left(e^{(b+\theta)(T-V / a)}-1\right)}{(b+\theta)^{2}}-\frac{a(T-V / a)}{b+\theta}\right]\right. \\
& \left.-p I_{e}\left[\frac{a \theta\left[\left(T_{c}\right)^{2}-t_{a}^{2}\right]}{2(b+\theta)}-\frac{a b\left[t_{a} e^{(b+\theta)\left(T_{c}-t_{a}\right)}-T_{c}\right]}{(b+\theta)^{2}}+\frac{a b\left[e^{(b+\theta)\left(T_{c}-t_{a}\right)}-1\right]}{(b+\theta)^{3}}\right]\right\}
\end{aligned}
$$

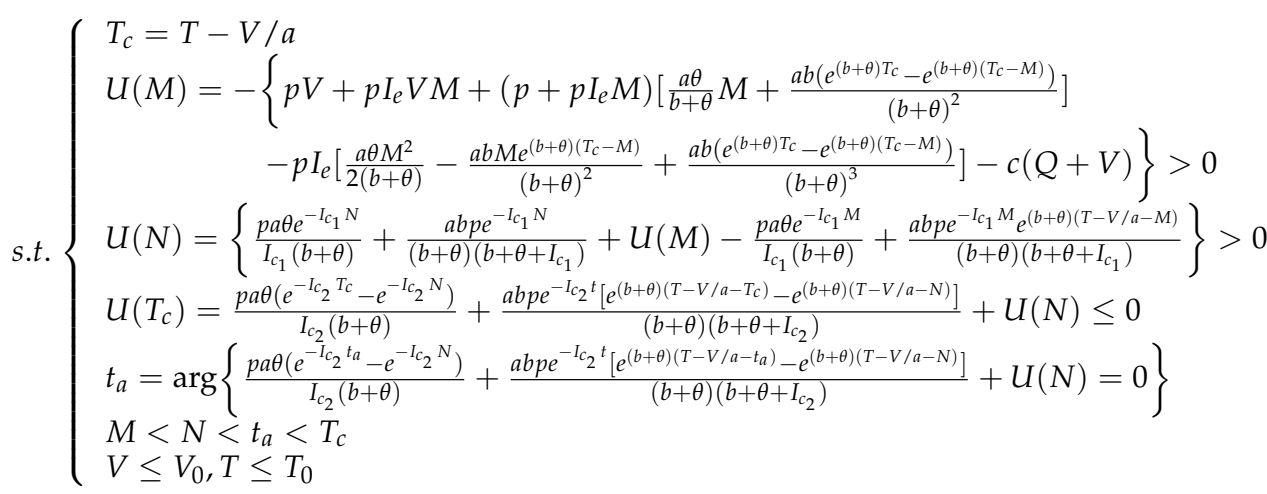


Subcase 3-2b'

$$
\begin{aligned}
& \underset{(T, V)}{\operatorname{Max}} A P_{3-2 b^{\prime}}(T, V)=\frac{1}{T}\left[p \int_{t_{b}}^{T_{c}} R(t) d t+p I_{e} \int_{t_{b}}^{T_{c}} R(t)(T-t) d t-A-c_{0} V-h \int_{0}^{T_{c}} Z(t) d t\right] \\
& =\frac{1}{T}\left\{\left(p+p I_{\mathcal{e}} T\right)\left[\frac{a \theta\left(T_{c}-t_{b}\right)}{b+\theta}+\frac{a b\left(e^{(b+\theta)\left(T_{c}-t_{b}\right)}-1\right)}{(b+\theta)^{2}}\right]-A-c_{0} V-h\left[\frac{a\left(e^{(b+\theta) T_{c}}-1\right)}{(b+\theta)^{2}}-\frac{a T_{c}}{b+\theta}\right]\right. \\
& \left.-p I_{e}\left[\frac{a \theta\left[\left(T_{c}\right)^{2}-t_{b}{ }^{2}\right]}{2(b+\theta)}-\frac{a b\left[t_{b} e^{(b+\theta)\left(T_{c}-t_{b}\right)}-T_{c}\right]}{(b+\theta)^{2}}+\frac{a b\left[e^{(b+\theta)\left(T_{c}-t_{b}\right)}-1\right]}{(b+\theta)^{3}}\right]\right\} \\
& \left\{\begin{array}{l}
T_{\mathcal{C}}=T-V / a \\
\phi(M)=\left\{p V+p I_{\mathcal{e}} V M+\left(p+p I_{\mathcal{e}} M\right)\left[\frac{a \theta}{b+\theta} M+\frac{a b\left(e^{(b+\theta) T_{\mathcal{C}}}-e^{(b+\theta)\left(T_{c}-M\right)}\right)}{(b+\theta)^{2}}\right]\right.
\end{array}\right. \\
& \left.-p I_{e}\left[\frac{a \theta M^{2}}{2(b+\theta)}-\frac{a b M e^{(b+\theta)\left(T_{c}-M\right)}}{(b+\theta)^{2}}+\frac{a b\left(e^{(b+\theta) T_{c}}-e^{(b+\theta)\left(T_{c}-M\right)}\right)}{(b+\theta)^{3}}\right]-c(Q+V)\right\}<0 \\
& \phi(N)=\left\{p\left(1+I_{\mathcal{e}} N\right)\left[\frac{a \theta(N-M}{b+\theta}\right)+\frac{a b\left(e^{(b+\theta)(N-M)}-1\right)}{(b+\theta)^{2}}\right]+\phi(M)\left[1+I_{\mathcal{C}_{1}}(N-M)\right] \\
& \text { s.t. }\left\{\quad-p I_{e}\left[\frac{a \theta\left(N^{2}-M^{2}\right)}{2(b+\theta)}-\frac{a b\left(M e^{(b+\theta)(N-M)}-T_{c}\right)}{(b+\theta)^{2}}+\frac{a b\left(e^{(b+\theta)(N-M)}-1\right)}{(b+\theta)^{3}}\right]\right\} \geq 0 \\
& t_{b}=\arg \left\{p\left(1+I_{e} t_{b}\right)\left[\frac{a \theta\left(t_{b}-M\right)}{b+\theta}+\frac{a b\left(e^{(b+\theta)\left(T_{c}-M\right)}-e^{(b+\theta)\left(T_{c}-t_{b}\right)}\right)}{(b+\theta)^{2}}\right]+\phi(M)\left[1+I_{\mathcal{C}_{1}}\left(t_{b}-M\right)\right]\right. \\
& \left.-p I_{e}\left[\frac{a \theta\left(t_{b}{ }^{2}-M^{2}\right)}{2(b+\theta)}-\frac{a b\left(M e^{(b+\theta)\left(T_{c}-M\right)}-x e^{(b+\theta)\left(T_{c}-t_{b}\right)}\right)}{(b+\theta)^{2}}\right]+\frac{a b\left(e^{(b+\theta)\left(T_{c}-M\right)}-e^{(b+\theta)\left(T_{c}-t_{b}\right)}\right)}{(b+\theta)^{3}}=0\right\} \\
& M<t_{b} \leq N \leq T_{c} \\
& V \leq V_{0}, T \leq \bar{T}_{0}
\end{aligned}
$$

Subcase 3-2b"

$$
\begin{gathered}
\underset{(T, V)}{\operatorname{Max}} A P_{3-2 b^{\prime \prime}}(T, V)=\frac{1}{T}\left[p \int_{t_{b}}^{T_{c}} R(t) d t+p I e \int_{t_{b}}^{T} R(t)(T-t) d t-A-c_{0} V-h \int_{0}^{T_{c}} Z(t) d t\right] \\
=\frac{1}{T}\left\{\left(p+p I_{e} T\right)\left[\frac{a \theta\left(T_{c}-t_{b}\right)}{b+\theta}+\frac{a b\left(e^{(b+\theta)\left(T_{c}-t_{b}\right)}-1\right)}{(b+\theta)^{2}}\right]-A-c_{0} V-h\left[\frac{a\left(e^{(b+\theta) T_{c}}-1\right)}{(b+\theta)^{2}}-\frac{a T_{c}}{b+\theta}\right]\right. \\
\left.-p I_{\mathcal{e}}\left[\frac{a \theta\left[\left(T_{c}\right)^{2}-t_{b}{ }^{2}\right]}{2(b+\theta)}-\frac{a b\left[t_{b} e^{(b+\theta)\left(T_{c}-t_{b}\right)}-T_{c}\right]}{(b+\theta)^{2}}+\frac{a b\left[e^{(b+\theta)\left(T_{c}-t_{b}\right)}-1\right]}{(b+\theta)^{3}}\right]\right\}
\end{gathered}
$$

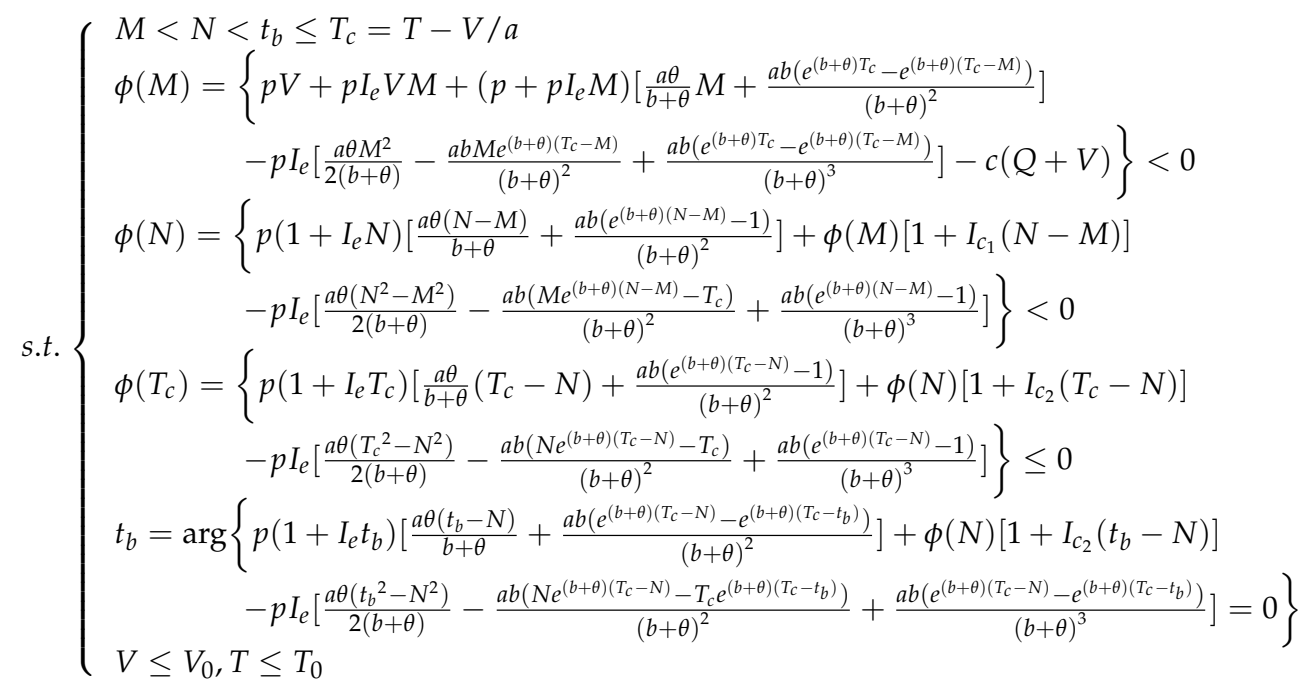

Case 4

$$
\begin{aligned}
& \underset{(T, V)}{\operatorname{Max}} A P_{4}(T, V)=\frac{1}{T}\left[U(M) I_{\mathcal{e}}(T-M)-A-c_{0} V-h \int_{0}^{T_{c}} Z(t) d t\right] \\
& =\frac{1}{T}\left\{U(M) I_{e}(T-M)-A-c_{0} V-h\left[\frac{a\left(e^{(b+\theta) T_{c}}-1\right)}{(b+\theta)^{2}}-\frac{a T_{c}}{b+\theta}\right]\right\} \\
& \text { s.t. }\left\{\begin{aligned}
& T_{\mathcal{C}}=T-V / a \\
& U(M)=\left\{\left(p+p I_{e} M\right)\left[V+\frac{a \theta T_{c}}{b+\theta}+\frac{a b\left(e^{(b+\theta) T_{c}}-1\right)}{(b+\theta)^{2}}\right]\right. \\
&\left.-p I_{e}\left[\frac{a \theta\left(T_{c}\right)^{2}}{2(b+\theta)}-\frac{a b T_{c}}{(b+\theta)^{2}}+\frac{a b\left(e^{(b+\theta) T_{c}}-1\right)}{(b+\theta)^{3}}\right]-c(Q+V)\right\} \geq 0 \\
& T_{c}<M<N \\
& V \leq V_{0}, T \leq T_{0}
\end{aligned}\right.
\end{aligned}
$$




\section{References}

1. Li, L.; Shubik, M.; Sobel, M.J. Control of Dividends, Capital Subscriptions, and Physical Inventories. Manag. Sci. 2013. [CrossRef]

2. Cachon, G. Supply chain coordination with contracts. In Handbooks in Operations Research and Management Science: Supply Chain Management: Design, Coordination and Operation; Graves, S., Kok, T.D., Eds.; North-Holland: Amsterdam, The Netherlands, 2003; pp. 229-340.

3. Aggarwal, S.P.; Jaggi, C.K. Ordering Policies of Deteriorating Items under Permissible Delay in Payments. J. Oper. Res. Soc. 1995, 46, 658-662. [CrossRef]

4. Sarker, B.R.; Jamal, A.M.M.; Wang, S. Supply chain models for perishable products under inflation and permissible delay in payment. Comput. Oper. Res. 2000, 27, 59-75. [CrossRef]

5. Soni, H.; Shah, N.H. Optimal ordering policy for stock-dependent demand under progressive payment scheme. Eur. J. Oper. Res. 2008, 184, 91-100. [CrossRef]

6. Pal, B. Optimal production model with quality sensitive market demand, partial backlogging and permissible delay in payment. RAIRO Oper. Res. 2017, 52, 499-512. [CrossRef]

7. Sen, N.; Saha, S. An inventory model for deteriorating items with time dependent holding cost and shortages under permissible delay in payment. Int. J. Procure. Manag. 2018, 11, 518. [CrossRef]

8. Levin, R.I.; McLaughlin, C.P.; Lamone, R.P.; Kottas, J.F. Productions Operations Management: Contemporary Policy for Managing Operating Systems; McGraw-Hill: New York, NY, USA, 1972.

9. Shukla, H.S.; Tripathi, R.P.; Sang, N. EOQ Model with Stock-Level Dependent Demand and Different Holding Cost Functions. Int. J. Oper. Res. Inf. Syst. (IJORIS) 2017, 8, 59-75. [CrossRef]

10. Fu, K.; Chen, Z. EPQ model for stock-dependent demand with learning effect of productivity. Comput. Integr. Manuf. Syst. 2016, 22, 2478-2486.

11. Li, R.; Lan, H.; Mawhinney, J.R. A Review on Deteriorating Inventory Study. J. Serv. Sci. Manag. 2010, 3, 117-129. [CrossRef]

12. Wang, S.P. An inventory replenishment policy for deteriorating items with shortages and partial backlogging. Comput. Oper. Res. 2002, 29, 2043-2051. [CrossRef]

13. Dye, C.Y. Joint pricing and ordering policy for a deteriorating inventory with partial backloggin. Omega 2007, 35, 184-189. [CrossRef]

14. Majumder, P.; Bera, U.K.; Maiti, M. An EPQ model for a deteriorating item with inflation reduced selling price and demand with immediate part payment. Hacet. Univ. Bull. Nat. Sci. Eng. 2014, 43, 641-659.

15. Ardak, P.S.; Borade, A.B.; Betlejewska, R.S. An epq model for deteriorating items with mix demand pattern. In. J. Mech. Eng. Technol. 2017, 8, 59-69.

16. Chang, H.J.; Dye, C.Y. An EOQ model for deteriorating items with time varying demand and partial backlogging. J. Oper. Res. Soc. 1999, 50, 1176-1182. [CrossRef]

17. Yang, C.T.; Ouyang, L.Y.; Wu, H.H. Retailer's Optimal Pricing and Ordering Policies for Non-Instantaneous Deteriorating Items with Price-Dependent Demand and Partial Backlogging. Math. Probl. En. 2009, 2009, 1-18. [CrossRef]

18. Khanra, S.; Ghosh, S.K.; Chaudhuri, K.S. An EOQ model for a deteriorating item with time dependent quadratic demand under permissible delay in payment. Appl. Math. Comput. 2011, 218, 1-9. [CrossRef]

19. Singh, T.; Pattnayak, H. An EOQ Model for a Deteriorating Item with Time Dependent Quadratic Demand and Variable Deterioration under Permissible Delay in Payment. Adv. Theor. Appl. Math. 2013, 7, 2939-2951. [CrossRef]

20. Pal, M.; Samanta, A. Inventory model for non-instantaneous deteriorating item with random pre-deterioration period. Int. J. Inventory Res. 2018, 5, 3-12. [CrossRef]

21. Chung, K.-J. A note on optimal ordering policies when the supplier provides a progressive interest scheme. Eur. J. Oper. Res. 2009, 199, 611-617. [CrossRef]

22. Goyal, S.K.; Teng, J.T.; Chang, C.T. Optimal ordering policies when the supplier provides a progressive interest scheme. Eur. J. Oper. Res. 2007, 179, 404-413. [CrossRef]

23. Mohan, S.; Mohan, G.; Chandrasekhar, A. Multi-item, economic order quantity model with permissible delay in payments and a budget constraint. Eur. J. Ind. Eng. 2008, 2, 446-460. [CrossRef]

24. Chen, S.C.; Teng, J.T. Retailer's economic order quantity when the supplier offers conditionally permissible delay in payments link to order quantity. Int. J. Prod. Econ. 2014, 155, 284-291. [CrossRef] 
25. Li, J.; Feng, H.; Zeng, Y. Inventory games with permissible delay in payments. Eur. J. Oper. Res. 2014, 234, 694-700. [CrossRef]

26. Vandana; Sharma, B.K. An EOQ model for retailers partial permissible delay in payment linked to order quantity with shortages. Math. Comput. Simul. 2016, 125, 99-112. [CrossRef]

27. Min, J.; Zhou, Y.-W. A perishable inventory model under stock-dependent selling rate and shortage-dependent partial backlogging with capacity constraint. Int. J. Syst. Sci. 2009, 40, 33-44. [CrossRef]

28. Lee, Y.-P.; Dye, C.-Y. An inventory model for deteriorating items under stock-dependent demand and controllable deterioration rate. Comput. Ind. Eng. 2012, 63, 474-482. [CrossRef]

29. Min, J.; Zhou, Y.-W.; Zhao, J. An inventory model for deteriorating items under stock-dependent demand and two-level trade credit. Appl. Math. Model. 2010, 34, 3273-3285. [CrossRef]

30. Sana, S.S. An EOQ model for salesmen's initiatives, stock and price sensitive demand of similar products-A dynamical system. Appl. Math. Comput. 2011, 218, 3277-3288. [CrossRef]

31. Sana, S.S. An EOQ model of homogeneous products while demand is salesmen's initiatives and stock sensitive. Comput. Math. Appl. 2011, 62, 577-587. [CrossRef]

32. Zhou, Y.-W.; Zhong, Y.; Li, J. An uncooperative order model for items with trade credit, inventory-dependent demand and limited displayed-shelf space. Eur. J. Oper. Res. 2012, 223, 76-85. [CrossRef]

33. Ray, J.; Chaudhuri, K.S. An EOQ model with stock-dependent demand, shortage, inflation and time discounting. Int. J. Prod. Econ. 1997, 53, 171-180. [CrossRef]

34. Teng, J.T.; Chang, C.T. Economic production quantity models for deteriorating items with price- and stock-dependent demand. Comput. Oper. Res. 2005, 32, 297-308. [CrossRef]

35. Teng, J.T.; Ouyang, L.Y. An EOQ model for deteriorating items with power-form stock-dependent demand. Int. J. Inf. Manag. Sci. 2005, 16, 1-16.

36. Tyagi, A.P.; Pandey, R.K.; Singh, S. An optimal replenishment policy for non-instantaneous deteriorating items with stock-dependent demand and variable holding cost. Int. J. Oper. Res. 2014, 21, 466. [CrossRef]

37. Ghosh, S.K.; Sarkar, T.; Chaudhuri, K. A Multi-Item Inventory Model for Deteriorating Items in Limited Storage Space with Stock-Dependent Demand. Am. J. Math. Manag. Sci. 2015, 34, 147-161. [CrossRef]

38. Teng, J.-T.; Krommyda, I.-P.; Skouri, K.; Lou, K.-R. A comprehensive extension of optimal ordering policy for stock-dependent demand under progressive payment scheme. Eur. J. Oper. Res. 2011, 215, 97-104. [CrossRef]

39. Glock, C.H.; Ries, J.M.; Schwindl, K. A note on: Optimal ordering policy for stock-dependent demand under progressive payment scheme. Eur. J. Oper. Res. 2014, 232, 423-426. [CrossRef]

40. Shi, Y.; Eberhart, R.C. Empirical study of particle swarm optimization. In Proceedings of the 1999 Congress on Evolutionary Computation, CEC 99, Washington, DC, USA, 6-9 July 1999; Volume 321, pp. 320-324.

41. Eberhart, R.C.; Shi, Y. Particle swarm optimization: Developments, applications and resources. In Proceedings of the 2001 Congress on Evolutionary Computation, Seoul, Korea, 27-30 May 2001; Volume 81, pp. 81-86. 